\title{
Barotropic Rossby Waves Radiating from Tropical Instability Waves in the Pacific Ocean
}

\author{
J. THOMAS FARRAR \\ Department of Physical Oceanography, Woods Hole Oceanographic Institution, Woods Hole, Massachusetts
}

(Manuscript received 6 August 2010, in final form 10 January 2011)

\begin{abstract}
Tropical instability waves are triggered by instabilities of the equatorial current systems, and their sea level signal, with peak amplitude near $5^{\circ} \mathrm{N}$, is one of the most prominent features of the dynamic topography of the tropics. Cross-spectral analysis of satellite altimetry observations shows that there is sea level variability in the Pacific Ocean as far north as Hawaii (i.e., $20^{\circ} \mathrm{N}$ ) that is coherent with the sea level variability near $5^{\circ} \mathrm{N}$ associated with tropical instability waves. Within the uncertainty of the analysis, this off-equatorial variability obeys the dispersion relation for nondivergent, barotropic Rossby waves over a fairly broad range of periods (26-38 days) and zonal wavelengths $\left(9^{\circ}-23^{\circ}\right.$ of longitude) that are associated with tropical instability waves. The dispersion relation and observed wave properties further suggest that the waves are carrying energy away from the instabilities toward the North Pacific subtropical gyre, which, together with the observed coherence of the sea level signal of the barotropic waves with that of the tropical instability waves, suggests that the barotropic Rossby waves are being radiated from the tropical instability waves. The poleward transport of kinetic energy and westward momentum by these barotropic Rossby waves may influence the circulation in the subtropics.
\end{abstract}

\section{Introduction}

Tropical instability waves (TIWs), a result of instability of the equatorial current systems of the Atlantic and Pacific Oceans, typically reach large amplitude in the Pacific during the boreal fall and winter months. The waves extract energy from the large-scale, wind-driven currents and have been extensively studied. TIW variability is one of the most prominent features of the surface dynamic topography of the tropics and the global ocean, with peak amplitudes in sea surface height occurring near $5^{\circ} \mathrm{N}$ in the Pacific (e.g., Miller et al. 1985; Malardé et al. 1987; Musman 1989; Périgaud 1990; Lyman et al. 2005; Farrar 2008; Shinoda et al. 2009). Almost all previous studies of tropical instability waves have focused on the immediate vicinity of the equator (about $8^{\circ} \mathrm{N}-8^{\circ} \mathrm{S}$ ). This study will show that TIW disturbances in the nearequatorial Pacific are associated with sea surface height variability in regions much farther from the equator (up to $20^{\circ} \mathrm{N}$, at least) and that this variability at higher latitudes, coherent with the near-equatorial TIW variability,

Corresponding author address: J. Thomas Farrar, Woods Hole Oceanographic Institution, Mail Stop 29, Woods Hole, MA 02543. E-mail: jfarrar@whoi.edu can be interpreted as being due to poleward radiation of barotropic Rossby waves from the instabilities.

The zonal wavenumber-frequency spectrum of sea surface height (SSH) anomaly in the Pacific [from the Archiving, Validation, and Interpretation of Satellite Oceanographic data (AVISO) gridded SSH product; section 2], when averaged over $7^{\circ} \mathrm{N}-7^{\circ} \mathrm{S}$, exhibits a pronounced and statistically significant spectral peak at periods near 33 days and wavelengths of $10^{\circ}-20^{\circ}$ of longitude (Fig. 1; see also Farrar 2008; Shinoda et al. 2009). This spectral peak is associated with TIWs, but a complete description cannot come from sea level fluctuations alone. The wide range of wavelengths and periods previously reported for TIWs (e.g., Table 1 of Qiao and Weisberg 1995, and references therein) and the multiple unstable modes found in linear stability analyses of the equatorial current system (e.g., McCreary and $\mathrm{Yu}$ 1992; Yu et al. 1995; Lyman et al. 2005) suggest that there are different instabilities occurring at different wavelengths and periods. It is becoming increasingly clear that there are strong disturbances that resemble mixed Rossbygravity waves, with higher frequencies (periods around 17 days), a strong meridional velocity signal on the equator, and a relatively weak sea level signal, as well as disturbances resembling equatorially trapped Rossby waves, 


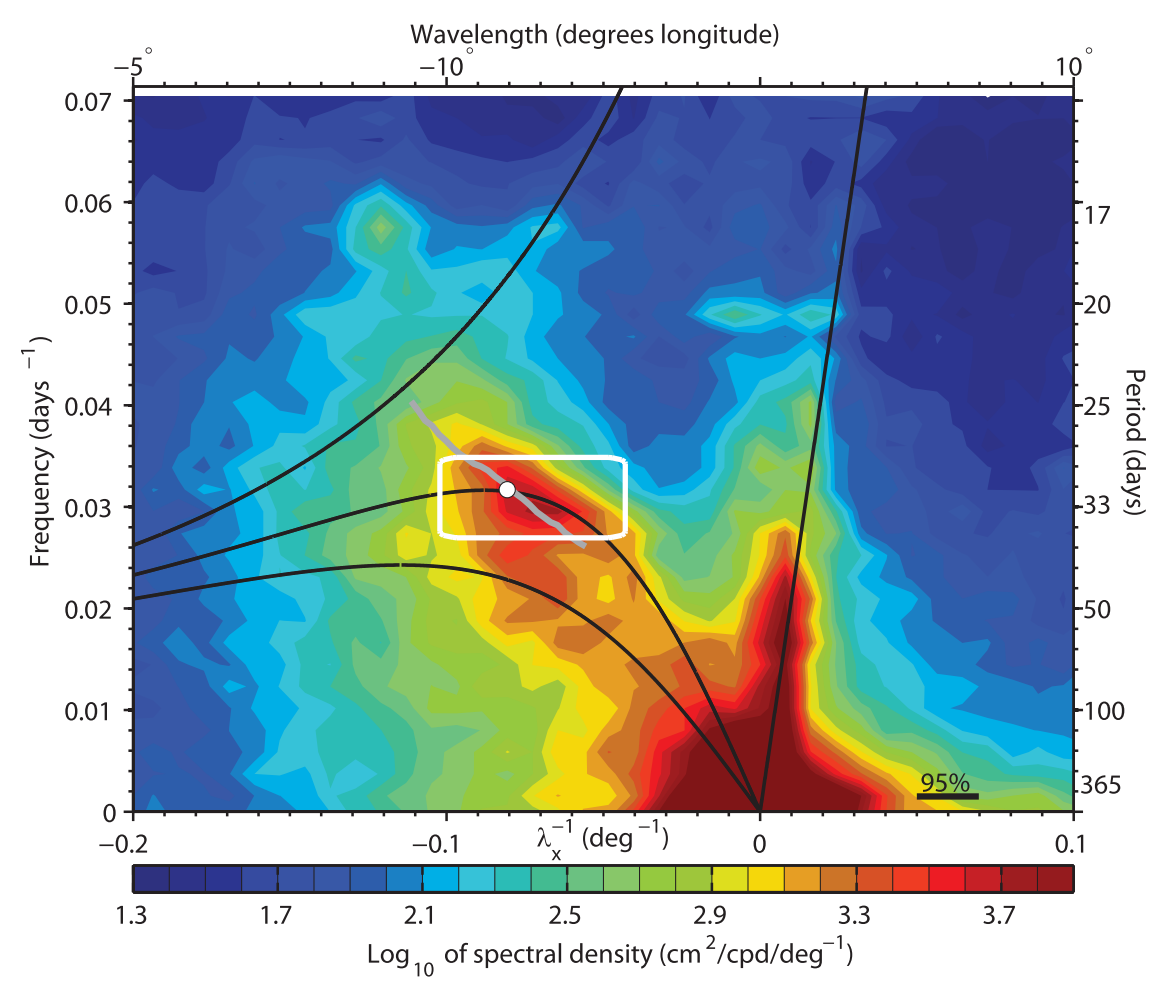

FIG. 1. Zonal-wavenumber-frequency spectrum of SSH, averaged over $7^{\circ} \mathrm{S}-7^{\circ} \mathrm{N}$. The white box indicates the half-power points of the filter used to examine SSH variability associated with the TIW spectral peak near periods of 33 days and zonal wavelengths of $12^{\circ}-17^{\circ}$ of longitude. Five dispersion curves are shown. The four black curves are the dispersion curves of the firstbaroclinic-mode Kelvin, mixed Rossby-gravity, and Rossby waves of linear equatorial wave theory (e.g., Matsuno 1966), shown for reference. A more realistic theoretical dispersion curve for the TIWs, derived by Lyman et al. (2005) from a linear stability analysis, is indicated by a thick gray curve. The white circle indicates the wavenumber and frequency of the most unstable mode of the Lyman et al. (2005) analysis. The 95\% confidence interval should be measured against the color scale. (A difference of about two contours is significant at $95 \%$ confidence.)

with periods around 33 days and large sea level signals and subsurface vertical displacements near $5^{\circ} \mathrm{N}$ (e.g., Miller et al. 1985; Halpern et al. 1988; McPhaden 1996; Lyman et al. 2007). The instabilities causing the 33-day spectral peak in SSH are sometimes referred to as "tropical instability vortices" to distinguish them from the shorter-period variability found on the equator (e.g., Kennan and Flament 2000; Foltz et al. 2004). Attention here will be focused on the "33-day TIWs" that have the largest SSH signal.

The theoretical and observed meridional SSH structure of these 33-day TIWs in the Pacific Ocean has been addressed recently by Lyman et al. (2005) and Farrar (2008), but the latitude where this variability has its maximum amplitude can be assessed directly by bandpass filtering the SSH anomaly to pass westward-propagating variability with periods of 29-36 days and zonal wavelengths of $10^{\circ}-20^{\circ}$ of longitude (half-power points shown in Fig. 1). The root-mean-square (RMS) amplitude of this filtered field, computed across longitude to yield a function of latitude and time, tends to have a maximum near $5^{\circ}-6^{\circ} \mathrm{N}$ (Fig. 2a). The 33-day TIWs also have a signal south of the equator, near $5^{\circ} \mathrm{S}$, but its amplitude is several times smaller, as expected from previous work (e.g., Chelton et al. 2000; Lyman et al. 2005; Farrar 2008).

More unexpectedly, there is also a signal in this zonalwavenumber-frequency band extending up to $20^{\circ} \mathrm{N}$. The signal is more apparent during years when the 33-day TIW variability is strong at $5^{\circ} \mathrm{N}$, such as near the beginning of 1996, 1999, and 2000 (Fig. 2a), which suggests that the increased amplitude in this wavenumber-frequency band on $10^{\circ}-20^{\circ} \mathrm{N}$ may be a result of the TIWs. A complementary view of the variability on $10^{\circ}-20^{\circ} \mathrm{N}$ in the filtered SSH field and its relationship to the 33-day TIW signal near $5^{\circ} \mathrm{N}$ comes from longitude-time plots of the filtered field from $5^{\circ}$ and $15^{\circ} \mathrm{N}$ (Fig. 2b), showing that there is also a reasonably close correspondence in longitude, as well as in time, of the filtered SSH field at $5^{\circ}$ and $15^{\circ} \mathrm{N}$. That there 

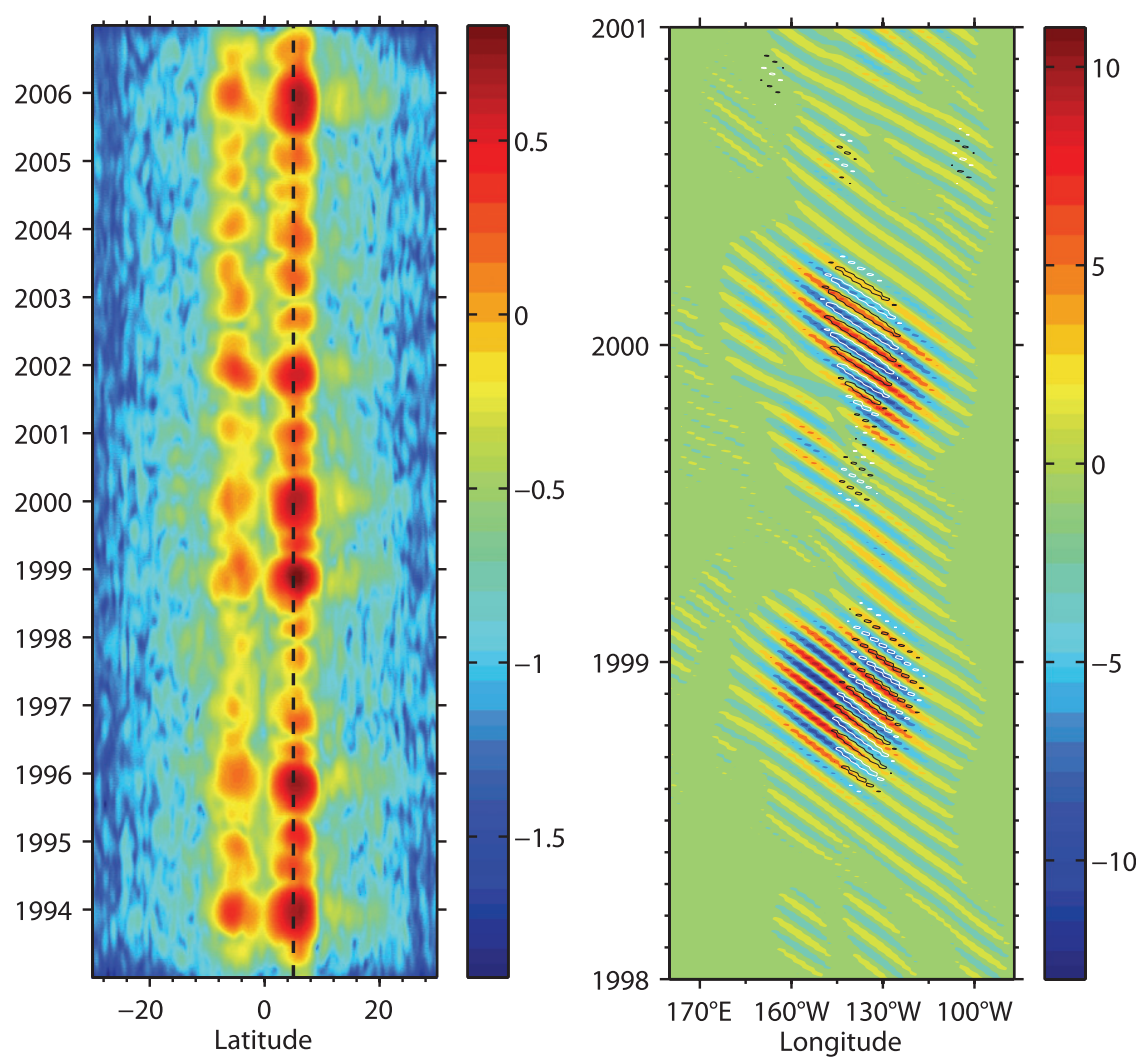

FIG. 2. Different presentations of the longitude-time bandpass-filtered SSH field described in the text (westward-propagating variability having wavelengths of $10^{\circ}-25^{\circ}$ of longitude and periods of 29-37 days). (left) Base-10 logarithm of the standard deviation of the filtered SSH field $(\mathrm{cm})$, computed across longitude to yield standard deviation as a function of latitude and time. The vertical, dashed line marks $5^{\circ} \mathrm{N}$. (right) Filtered SSH along $5^{\circ} \mathrm{N}$ (cm; colors), with filtered SSH along $15^{\circ} \mathrm{N}$ contoured at $\pm 0.5 \mathrm{~cm}$ (white and black contours).

should be any wavelike, westward-propagating variability in $\mathrm{SSH}$ at 30-day periods and latitudes as high as $15^{\circ} \mathrm{N}$ was initially a surprise, because a baroclinic Rossby wave north of $10^{\circ} \mathrm{N}$ would not be expected to exist at periods less than about 60 days (under linear, quasigeostrophic dynamics).

With a focus on the Pacific Ocean, we will argue that instability of the equatorial current system leads to radiation of barotropic Rossby waves over a range of frequencies and wavenumbers, carrying energy and westward momentum away from the equator toward midlatitudes. This result was presaged, remarkably, by the first general circulation model (GCM) study of TIWs (Fig. 12 of Cox 1980), and similar variability was also seen in the GCM study of Song and Zlotnicki (2004). Proehl (1996) performed a linear stability analysis for an equatorial zonal-channel model with boundaries at $10^{\circ} \mathrm{N}$ and $10^{\circ} \mathrm{S}$, and he found unstable modes that included barotropic variability on $7^{\circ}-10^{\circ} \mathrm{N}$ and $7^{\circ}-10^{\circ} \mathrm{S}$, near the poleward edge of the model domain (Fig. 11 of Proehl 1996, and associated text). Aside from these modeling studies, there has been scant attention given to the possibility that TIWs could have any direct effects outside of the near-equatorial region.

The role of these meridionally propagating, barotropic Rossby waves in the dynamics of TIWs and the equatorial and midlatitude circulation is not clear, but there are a number of reasons that the barotropic waves discussed here are of interest. First, although there is evidence that the oceans contain barotropic Rossby waves driven by atmospheric forcing (e.g., Luther 1982; Brink 1989; Samelson 1990; Luther et al. 1990; Chave et al. 1992; Niiler et al. 1993; Warren et al. 2002) and ones emanating from unstable western boundary currents (e.g., Price and Rossby 1982; Bower and Hogg 1992; Miller et al. 2007), the waves are difficult to observe with in situ measurements, and examples of barotropic Rossby waves in the satellite altimetry record are scarce and have apparently been limited to resonant modes of abyssal basins (Fu et al. 2001; Warren et al. 2002; Weijer 2008; Weijer et al. 2007, 2009). The waves discussed here are arguably the first example in the satellite altimetry record of free barotropic Rossby waves 
resembling plane waves and obeying the classical barotropic Rossby wave dispersion relation. Second, as discussed by Song and Zlotnicki (2004), barotropic waves at 30-day periods can introduce sampling errors in satellite measurements intended to map the earth's geoid. Third, with the constellation of satellite altimeters being one of the most extensive global observing networks for ocean dynamics, it is important to understand the extent to which different types of motions (e.g., baroclinic versus barotropic) contribute to SSH variability. Finally, radiation of barotropic (and baroclinic) Rossby waves from unstable currents is expected to contribute to the mesoscale eddy field in remote regions (e.g., Pedlosky 1977; Harrison and Robinson 1979; Malonette-Rizzoli et al. 1987; Bower and Hogg 1992; Tai and White 1990; Spall 1992). Understanding the origins of the mesoscale eddy field and the extent to which it is remotely generated is one of the foremost challenges in physical oceanography and is seemingly essential to development of physically realistic parameterizations of the effect of unresolved mesoscale variability in climate models.

\section{Data and methods}

The analysis uses the gridded SSH anomaly data product distributed by AVISO and constructed using crosscalibrated data from the various satellite altimeters that have been functioning since 1992 (Le Traon et al. 1998, 2003; Ducet et al. 2000; Pascual et al. 2006). The particular data product is the Delayed-Time Merged Sea Level Anomaly, Updated (DT-MSLA Upd). The data are gridded using objective analysis (Le Traon et al. 1998, 2003; Ducet et al. 2000). We use a version of the AVISO SSH product that has been spatially interpolated from the 7-day, $1 / 3^{\circ}$ Mercator mapping to a $1 / 4^{\circ} \times 1 / 4^{\circ} \times 7$-day Cartesian grid. The effective spatial resolution of the AVISO "reference" SSH product, which differs from the one used here in that only two altimeters are used at any given time, is believed to be about $2^{\circ}$ by $2^{\circ}$ on average (Ducet et al. 2000; Chelton et al. 2011).

The domain used for the calculations here is $148.75^{\circ} \mathrm{E}-$ $87.5^{\circ} \mathrm{W}$ and 1 January $1993-31$ December 2006. Latitudes of $45^{\circ} \mathrm{S}-45^{\circ} \mathrm{N}$ were examined, but attention here will mostly be restricted to latitudes of $15^{\circ} \mathrm{S}-25^{\circ} \mathrm{N}$. Because information at adjacent latitudes separated by $0.25^{\circ}$ is largely redundant because of the spatial smoothing in the gridding procedure, only every other latitude of the gridded product (i.e., $0.5^{\circ}$ increment) was used in the cross-spectral calculations.

Spectral and cross-spectral estimates were computed as a function of zonal wavenumber and frequency using a two-dimensional fast Fourier transform (FFT). Prior to computation of the FFT, gaps in the data due to islands were filled by linear interpolation in longitude and the mean was removed from each longitude-time section. The edges of the longitude-time section from each latitude were tapered to zero over 154 days and $10^{\circ}$ of longitude using Tukey (i.e., tapered cosine) windows to reduce edge effects in the spectral computations. At latitudes where a continental landmass encroached into the domain, the longitude tapering was performed on the seaward side of the land-sea edge.

Continental landmasses were assigned an SSH anomaly of zero (i.e., the longitude-time sections were zero padded so that each section had the same zonal width). No attempt was made to correct for variance deficits associated with the zero padding or tapering. The purpose of zero padding is to ensure that the longitude-time sections have the same size at each latitude to facilitate crossspectral computations between different latitudes while including the eastern equatorial Pacific, where TIWs are strong, within the domain. An alternative way of accomplishing the same end is to shift the zonal domain as a function of latitude, which is inconvenient because it introduces a latitude- and zonal-wavelength-dependent phase shift in the cross-spectral calculations. This was done, and the results were qualitatively unchanged.

Some qualitative and descriptive conclusions will be drawn from SSH data that are filtered in frequency and zonal wavenumber. These filtered fields were produced by performing a 2D FFT on the de-meaned and tapered longitude-time section from each latitude (independently), applying a taper window (Tukey) to isolate the frequencies and wavenumbers of interest while reducing filter sidelobes and transforming back to the longitudetime domain. Because the main result of this paper involves small SSH signals at off-equatorial latitudes $\left(10^{\circ}-\right.$ $25^{\circ} \mathrm{N}$ ) associated with large $\mathrm{SSH}$ signals near $5^{\circ} \mathrm{N}$, it should be emphasized that this filtering procedure cannot lead to "ringing" (i.e., Gibbs phenomenon) at one latitude resulting from strong variability at another latitude because the filtering procedure treats each latitude independently.

The principal methods used for quantitative inference involve cross-spectral calculations (coherence amplitude, phase, and gain) between longitude-time sections of SSH at different latitudes as a function of zonal wavenumber and frequency. The procedure is almost identical to the one used by Farrar (2008), and a complementary description is given there. The cross-spectrum and associated quantities (coherence amplitude, phase, and gain) were calculated between $5^{\circ} \mathrm{N}$ and all other latitudes. The latitude of $5^{\circ} \mathrm{N}$ was chosen as a reference latitude in an attempt to isolate $\mathrm{SSH}$ variability that is associated with the 33-day TIWs that have their maximum SSH amplitude near $5^{\circ} \mathrm{N}$. To increase the degrees of freedom and statistical reliability of the 
estimates, band averaging was performed over blocks of 11 frequency bands (with no overlap) to yield an estimated 22 degrees of freedom for the spectral estimates. ${ }^{1}$ This results in estimates of the coherence amplitude, phase, and gain (or the relative amplitude of coherent variability), relative to $5^{\circ} \mathrm{N}$, as a function of latitude, zonal wavenumber, and frequency. Estimates of significance levels for the coherence amplitude and confidence intervals for the coherence phase and gain were computed following Bendat and Piersol (1986), and the coherence phase and gain estimates are shown only when the coherence amplitude is deemed significant at $95 \%$ confidence.

The autospectrum shown in Fig. 1 (and Fig. 8) was computed by averaging autospectra from each latitude on $7^{\circ} \mathrm{S}-7^{\circ} \mathrm{N}$. The rationale for doing this was discussed by Farrar (2008). After averaging the spectra over latitude and band averaging over blocks of 11 frequency bands, the number of degrees of freedom was estimated to be 198 under the assumption that latitudes $1.5^{\circ}$ apart contribute independent information. This assumption affects only the size of the error bars in Fig. 1 (and Fig. 8) and is not critical to the inferences in this paper.

\section{Results and interpretation}

\section{a. A wavelike signal on $10^{\circ}-20^{\circ} \mathrm{N}$ with a period of about 30 days}

When the SSH anomaly is filtered to pass westwardpropagating variability with periods of 29-37 days and zonal wavelengths of $10^{\circ}-25^{\circ}$ of longitude, one can see the existence of variability on $10^{\circ}-20^{\circ} \mathrm{N}$ resembling a plane wave with wave crests oriented southeast-northwest (Figs. 3, 4). Although it is not obvious from inspection of the filtered field at a particular time, the phase propagation is to the southwest. Animations of the filtered field (not shown) and Fig. 2 suggest that this variability is likely coupled to or caused by the more energetic TIW variability near the equator.

The wavelike signal seen on $10^{\circ}-20^{\circ} \mathrm{N}$ in the filtered field (e.g., Fig. 3c) is not at all evident in the "raw" (i.e., unfiltered) gridded SSH product (Fig. 3a) and is admittedly of small amplitude $(0.5-1.5 \mathrm{~cm})$, so one may wonder

\footnotetext{
${ }^{1}$ Results are presented here with $95 \%$ confidence intervals computed assuming there are 22 degrees of freedom in the spectral estimates. There are admittedly fewer than 22 degrees of freedom, because, for example, the time-domain tapering introduces linear dependencies in frequency. Therefore, the error estimates and significance levels given here should be regarded with some caution. If a more conservative estimate of the number of degrees of freedom is preferred, note that one would arrive at results that are quantitatively almost identical by assuming 18 degrees of freedom and examining results deemed significant at $90 \%$ confidence.
}

(a)

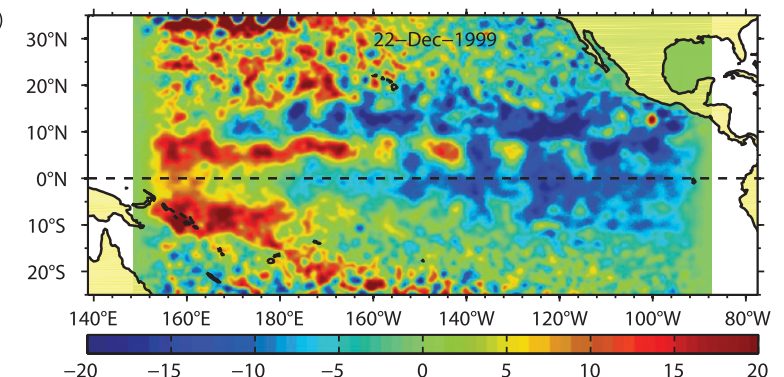

(b)
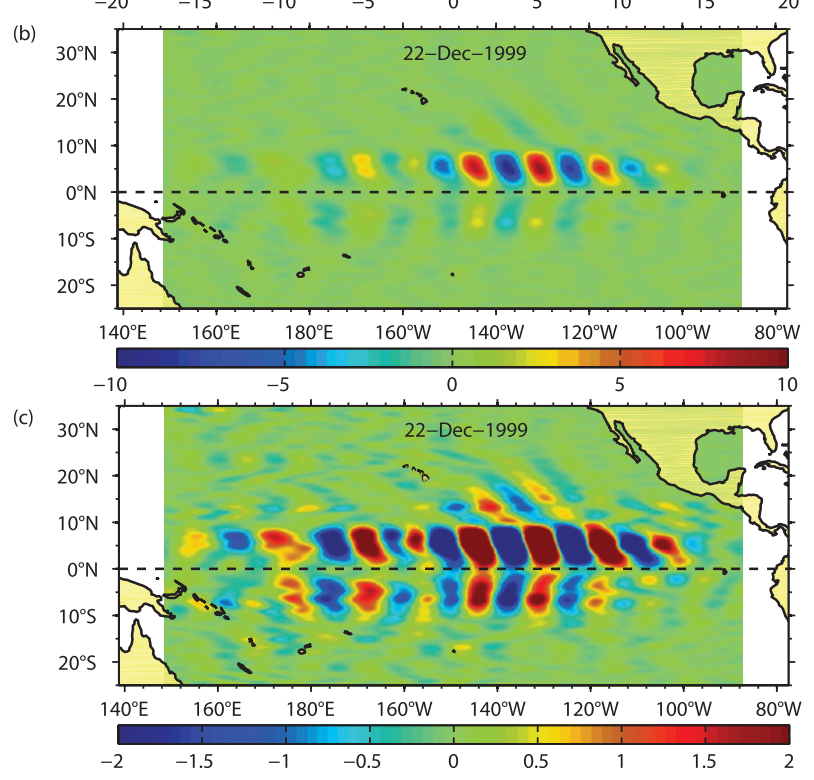

FIG. 3. The (top) SSH anomaly (cm) on 22 Dec 1999 (no filtering except removal of time-longitude mean at each latitude). (middle) Filtered SSH anomaly for the same day, using longitude-time bandpass filter described in the text (westward-propagating variability having wavelengths of $10^{\circ}-25^{\circ}$ of longitude and periods of 29-37 days). (bottom) As in (middle), but the color scale has been saturated to make the wavelike pattern on $10^{\circ}-20^{\circ} \mathrm{N}, 120^{\circ}-160^{\circ} \mathrm{W}$ more visible. All panels are in centimeters, but note the change of color scale. The amplitude of noise within the filter passband is expected to be on the order of a few millimeters.

whether the signal could be a result of bandpass filtering of noise in the SSH product. Lacking an estimate of the spectrum of the noise due to measurement, sampling, and mapping errors, this question is difficult to address quantitatively, but the issue is discussed in appendix A. The conclusion of that discussion is that, even though the amplitude of the bandpass-filtered signal is small, it is probably not below the detection threshold of the merged altimetry product, because only a small fraction of the noise variance should contaminate this particular wavenumberfrequency band. (If the noise spectrum were white, only about $3.5 \%$ of the noise variance would be expected to appear in the passband.)

A related concern is that the signal could be an artifact caused by the data processing (e.g., the filtering). Various 

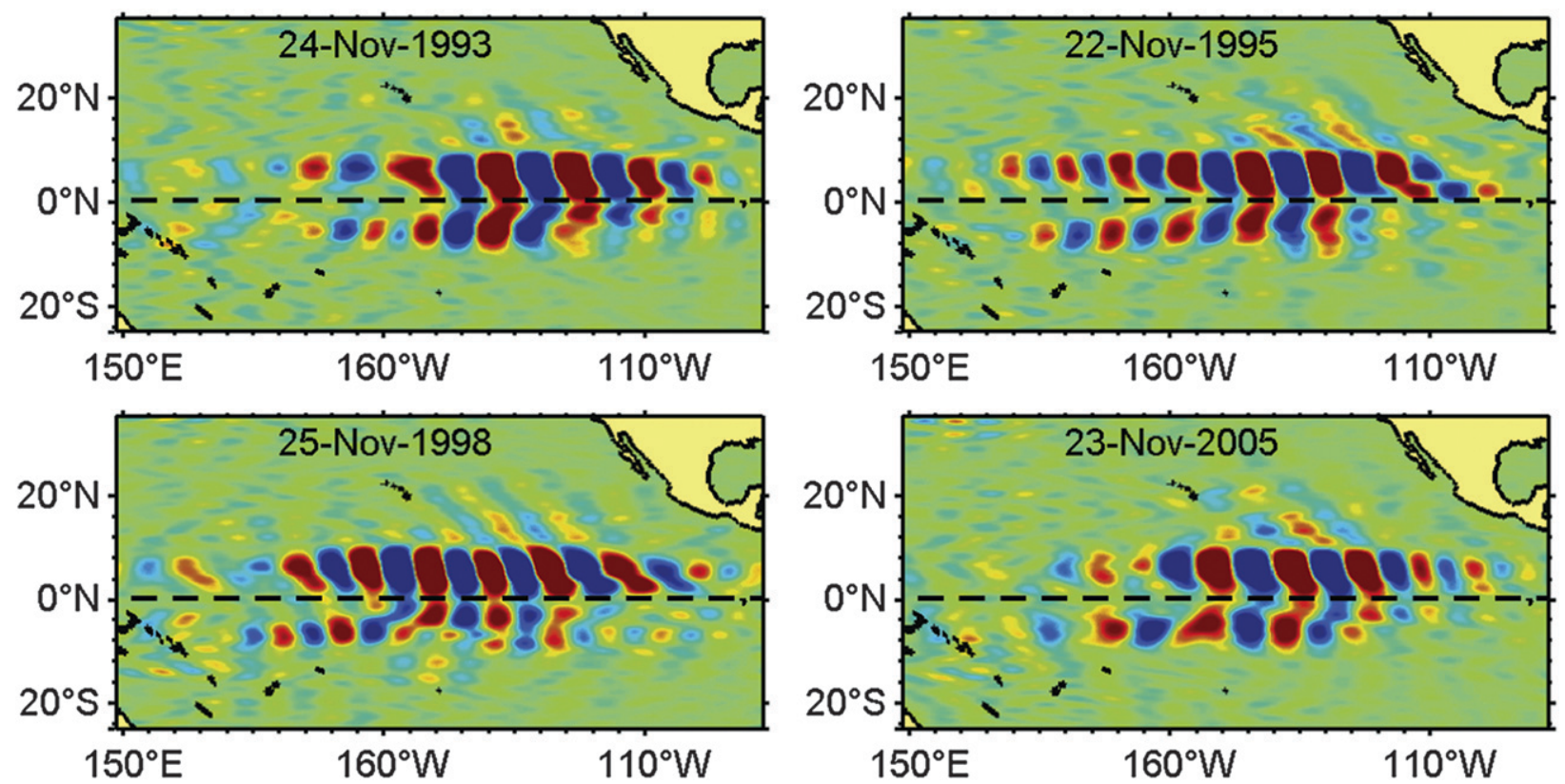

FIG. 4. Filtered SSH anomaly around the same time of year during 4 different years. The color scale is as in Fig. $3 \mathrm{c}$, saturating at $\pm 2 \mathrm{~cm}$. The wavelike pattern seen on $10^{\circ}-20^{\circ} \mathrm{N}, 120^{\circ}-150^{\circ} \mathrm{W}$ is present in each of the years shown, but the wave properties (zonal wavelength, period, crest orientation, and meridional extent) vary from year to year.

other filters and passbands were used, with no appreciable change in the results. Furthermore, the filter used here can hardly be considered narrowband, because the passband contains more than 500 Fourier harmonics. It will later be shown that the variability on $10^{\circ}-20^{\circ} \mathrm{N}$ is actually coherent with the much stronger variability at $5^{\circ} \mathrm{N}$ in this wavenumber-frequency band and that the variability on $10^{\circ}-20^{\circ} \mathrm{N}$ obeys the barotropic Rossby wave dispersion relation: these facts would be hard to explain as noise/ data/processing artifacts.

The wavelike signal seen on $10^{\circ}-20^{\circ} \mathrm{N}$ is a regular occurrence that appears to be linked to the tropical instability waves near $5^{\circ} \mathrm{N}$. It is clear from the zonal standard deviation of the filtered field (Fig. 2a) that the amplitude of the filtered variability tends to be larger on $10^{\circ}-20^{\circ} \mathrm{N}$ when it is larger at $5^{\circ} \mathrm{N}$, with elevated amplitudes occurring at both latitudes during the strong TIW years of 1993, 1995, 1998, 1999, 2001, and 2005. The wavelike signal on $10^{\circ}-20^{\circ} \mathrm{N}$ is most apparent late in the year after the TIWs have reached large amplitude. Inspection of the filtered field in late November during several different years (1993, 1995, 1998, and 2005; Fig. 4) shows that the signal is qualitatively similar in the different years, though there are year-to-year differences in the amplitude, the zonal wavelength, the orientation of the wave crests, and the meridional extent of the signal.

During years when the wavelike signal on $10^{\circ}-20^{\circ} \mathrm{N}$ occurs, it is usually discernible in the filtered field by around August and often remains discernible for about
6 months. An example of the temporal evolution of the filtered field is given in Fig. 5, which shows a sequence of images at 9-week increments during 1999-2000. During June 1999, the TIWs were only starting to develop near $5^{\circ} \mathrm{N}$ and there was no clear wave signal north of $10^{\circ} \mathrm{N}$. By mid-August, a wavelike pattern had started to develop on $10^{\circ}-15^{\circ} \mathrm{N}$ near $130^{\circ} \mathrm{W}$, and the pattern became more clearly defined, strengthened, and extended farther northward through the end of the year (October and December panels of Fig. 5). By late February, the amplitude of the signal had begun to decrease on $10^{\circ}-20^{\circ} \mathrm{N}$, but the signal extended north of Hawaii (perhaps to $25^{\circ} \mathrm{N}$ ) by that time. By late April, the signal had clearly weakened and was arguably no longer present, and this weakening continued through June 2000 (not shown). This sequence is representative of the years when TIW variability is strong on $5^{\circ} \mathrm{N}(1993,1995,1998,1999,2001$, and 2005). The wavelike signal is visible on $10^{\circ}-20^{\circ} \mathrm{N}$ during years of weaker TIW variability, but the amplitude is weaker and the time period when it can be seen is shorter.

Because the sea level signal of TIWs is largest near $5^{\circ} \mathrm{N}$ and the filtered field suggests that the variability at higher latitudes may be causally connected to the TIWs, it is natural to ask whether the off-equatorial variability is coherent, at a statistically significant level, with the SSH variability on $5^{\circ} \mathrm{N}$ in the zonal-wavenumber-frequency bands that we associate with TIWs. The coherence amplitude, gain, and phase of SSH variability between $5^{\circ} \mathrm{N}$ and other latitudes were computed as a function of zonal 

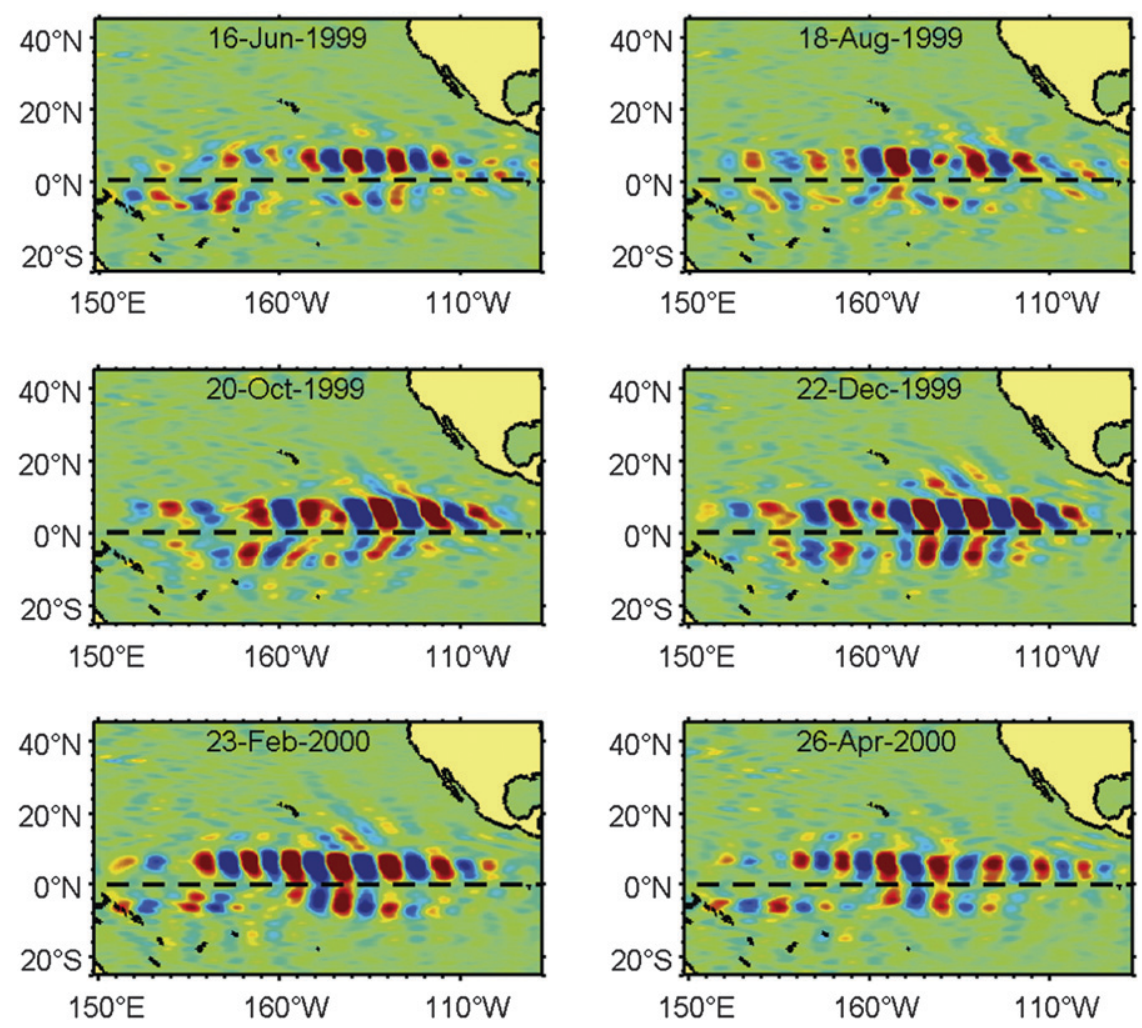

FIG. 5. Filtered SSH anomaly at different times during 1 TIW season (9-week increments). The color scale is as in Fig. 3c, saturating at $\pm 2 \mathrm{~cm}$.

wavenumber, frequency, and latitude (section 2). Meridional profiles of the gain and phase relative to $5^{\circ} \mathrm{N}$ are shown in Figs. 6a,b for a particular zonal-wavenumberfrequency band, centered at a period of 31.5 days and a wavelength of $12.4^{\circ}$ of longitude and within the broader 33-day TIW spectral peak (it is the band indicated by a white circle in Fig. 1). The observational gain/phase estimates are shown only at latitudes where the coherence amplitude is deemed significant at $95 \%$ confidence or better, so one can immediately draw from Figs. $6 a, b$ the important conclusion that there is variability in this wavenumber-frequency band on $10^{\circ}-$ $20^{\circ} \mathrm{N}$ that is coherent with that at $5^{\circ} \mathrm{N}$.

This coherent variability on $10^{\circ}-20^{\circ} \mathrm{N}$, with phase increasing almost linearly with latitude, is essentially the same variability seen in the filtered SSH field. This can be made more obvious by noting that $360^{\circ}$ of phase is equal to one zonal wavelength, which is, in this case, $12.4^{\circ}$ of longitude. Thus, the meridional profile of phase can be plotted in longitude and latitude at a fixed time (Fig. 6c). In Fig. 6c, the cross-spectral estimate of the meridional phase profile from Fig. $6 \mathrm{~b}$ has been overplotted four times on the filtered field (22 December 1999, as in Fig. 3), and the sets of black error bars and white error bars have been displaced zonally from one another by one-half wavelength (i.e., $6.2^{\circ}$ of longitude). ${ }^{2}$ It is clear that the cross-spectral phase estimate in this wavenumber-frequency band is representative of the most energetic SSH variability seen in the filtered field. (Cross-spectral phase estimates for nearby wavenumbers and frequencies, shown later, are similar and are equally representative.)

\footnotetext{
${ }^{2}$ It would be understandable if the reader found Fig. $6 \mathrm{c}$ confusing. Note first that the phase estimate shown in Fig. $6 \mathrm{~b}$ can be interpreted as a line of constant wave phase in latitude and longitude. (Recall that $360^{\circ}$ of phase is one wavelength, which is $12.4^{\circ}$ of longitude for this zonal-wavenumber-frequency band.) In other words, the phase estimate shown in Fig. 6 b can be interpreted as the spatial shape of a line tracing a wave crest, a wave trough, or a zero crossing. The phase estimate shown in Fig. $6 \mathrm{~b}$ has been rotated counterclockwise by $90^{\circ}$ for display in Fig. 6c (i.e., latitude is the horizontal axis in Fig. $6 \mathrm{~b}$ and it is the vertical axis in Fig. 6c). The zonal placement in Fig. $6 \mathrm{c}$ of one of these lines of constant phase is arbitrary, but the black lines and white lines represent opposite phases (e.g., local maxima and minima) for the zonal-wavenumberfrequency band of the coherence phase estimate (because the black lines are shifted westward from the white lines by half of a zonal wavelength).
} 
(a)

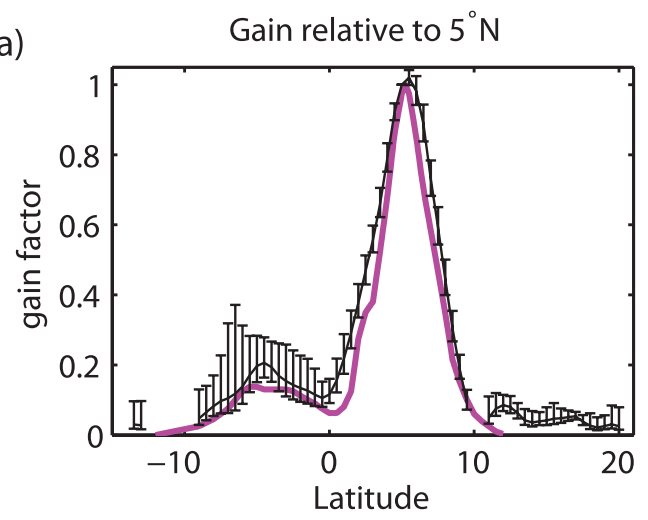

(c)

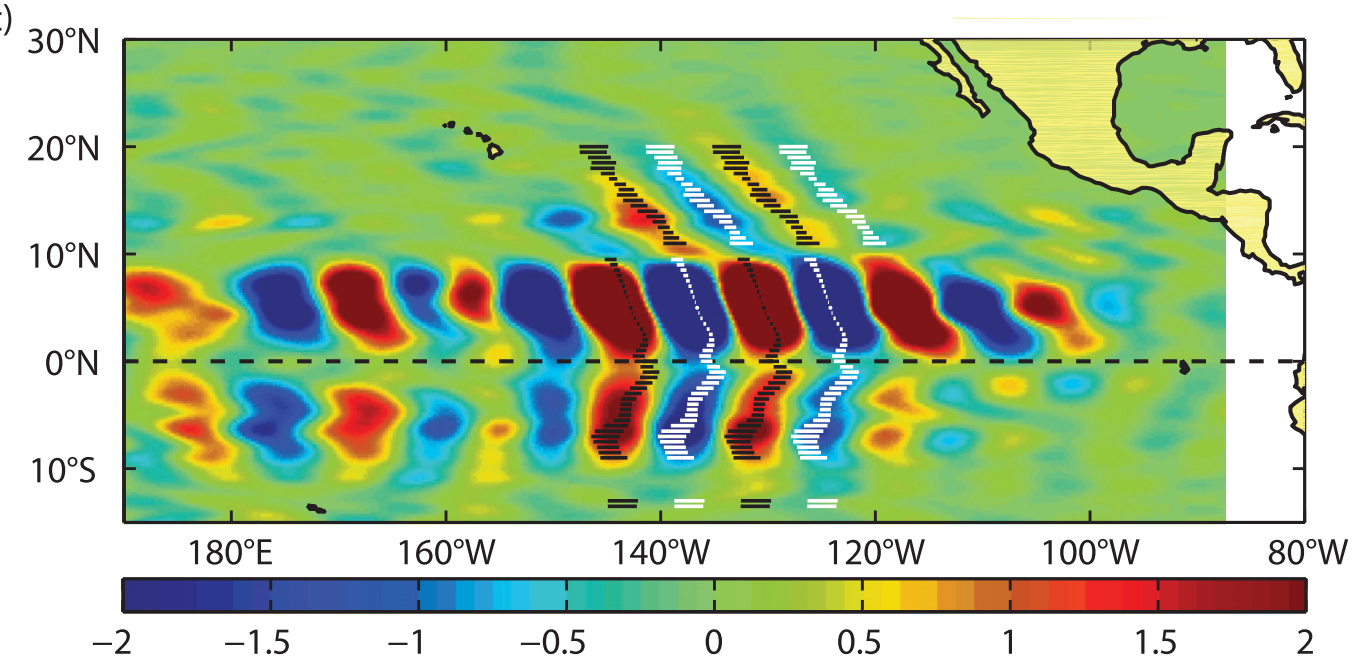

FIG. 6. (a) Gain and (b) coherence phase of SSH variability relative to $5^{\circ} \mathrm{N}$ in the zonal-wavenumber-frequency band corresponding to 31.5 -day periods and $12.4^{\circ}$ zonal wavelengths (marked in Fig. 1). Black lines are observational estimates, and pink lines are the theoretical prediction of Lyman et al. (2005) for the most unstable TIW mode, which was predicted to occur at this same zonal wavenumber and frequency. (c) Filtered SSH anomaly (cm) for 22 Dec 1999 (color shading; as in Fig. 3c), using longitude-time bandpass filter described in the text (westward-propagating variability having wavelengths of $10^{\circ}-25^{\circ}$ of longitude and periods of 29-37 days). Black and white lines are the coherence phase relative to $5^{\circ} \mathrm{N}$, as in (b), including the error bars, but they are plotted here as a function of latitude and longitude at a fixed time. The black lines and the white lines are offset in longitude by half a wavelength $\left(6.2^{\circ}\right.$ of longitude or $180^{\circ}$ of phase).

Both the cross-spectral phase estimate and the filtered field exhibit a phase discontinuity moving northward across $10^{\circ} \mathrm{N}$, where phase changes abruptly by about $180^{\circ}$. This abrupt meridional phase shift is a common but not entirely universal feature of nearby zonal-wavenumberfrequency bands, as will be shown later. Further discussion of the meridional phase discontinuity seen near $10^{\circ} \mathrm{N}$ will be offered in section 4 (discussion), after further analysis and interpretation of the wavelike variability on $10^{\circ}-20^{\circ} \mathrm{N}$.

The wavelength and frequency of the gain and phase estimates shown in Fig. 6 are the same wavelength and frequency (within the resolution of the spectral computation) as the fastest growing mode of the linear stability

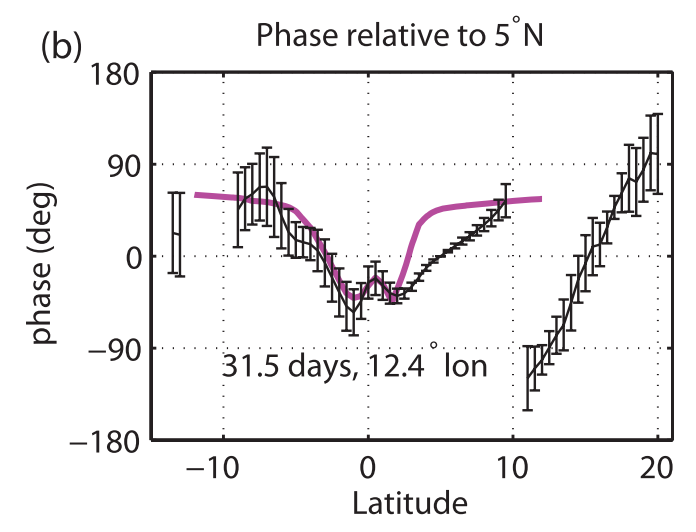


also predicted fairly well by the linear stability analysis: both theory and observation indicate that SSH is in phase at $10^{\circ} \mathrm{S}$ and $10^{\circ} \mathrm{N}$ and that $\mathrm{SSH}$ at $10^{\circ} \mathrm{S}$ and $10^{\circ} \mathrm{N}$ leads that at the equator by about $90^{\circ}$, as required to produce Reynolds stresses that can extract energy from the meridionally sheared large-scale zonal flow (Lyman et al. 2005). Even the detailed structure of the phase profile near the equator, with local minima of phase near $1^{\circ} \mathrm{S}$ and $2^{\circ} \mathrm{N}$ and a local maximum at $0.5^{\circ} \mathrm{N}$, is in agreement between the two estimates (see Farrar 2008).

Although the analysis of Lyman et al. probably contains most of the basic physics of the initial development of the instability, there are some conspicuous points of disagreement between the theoretical and observational estimates. Most obviously, the two estimates of the phase differ substantially, by about $45^{\circ}$, near $5^{\circ} \mathrm{N}$. This disagreement might have something to do with finite-amplitude effects or with the fact that the analysis of Lyman et al. did not include a barotropic mode. Another conspicuous point of disagreement is that sea level variability in this wavenumber-frequency band is coherent with that at $5^{\circ} \mathrm{N}$ at essentially all latitudes up to $20^{\circ} \mathrm{N}$, with the relative amplitude of the coherent $\mathrm{SSH}$ variability (i.e., the gain) being about $5 \%-10 \%$ as large on $10^{\circ}-20^{\circ} \mathrm{N}$ as it is at $5^{\circ} \mathrm{N}$, whereas the theoretical estimate of the amplitude made by Lyman et al. goes to zero near $12^{\circ} \mathrm{N}$. In the next subsection, we will investigate the hypothesis that this variability on $10^{\circ}-20^{\circ} \mathrm{N}$ is a result of barotropic Rossby waves radiated from the tropical instability waves.

\section{b. Interpretation as barotropic Rossby waves}

The filtered SSH anomalies displayed in Figs. 3 and 4 bear a close resemblance to fields shown in the GCM studies of Cox (1980) and Song and Zlotnicki (2004), which showed the barotropic streamfunction with similar filtering and ocean bottom pressure, respectively. Cox (1980) made clear that the variability seen at higher latitudes in his model was a result of the TIWs and that the signal was barotropic. The velocity amplitude of the barotropic variability in Cox's model was $1-2 \mathrm{~cm} \mathrm{~s}^{-1}$ at latitudes $10^{\circ}-15^{\circ}$ off the equator, about the same as the values inferred from application of the geostrophic relation to the filtered SSH field (not shown). Song and Zlotnicki (2004) referred to the signal in their model as an "ocean bottom pressure wave," but the presence of a wavelike signal in ocean bottom pressure is certainly suggestive of barotropic waves. Cox (1980) interpreted the signal in his model as poleward radiation of barotropic Rossby waves from the region of instability. This interpretation, an obvious one for a wavelike signal seen in the barotropic streamfunction, seems the most plausible one for 30 -day SSH variability on $10^{\circ}-20^{\circ} \mathrm{N}$, because linear theory for baroclinic Rossby waves suggests they should not exist at these latitudes at periods less than 60 days unless there is some systematic influence, such as from the mean flow or bottom topography (e.g., Killworth and Blundell 2004; Farrar and Weller 2006), causing the baroclinic waves to exist beyond their classical turning latitude (i.e., at frequencies higher than the maximum frequency expected at a given latitude under linear theory; e.g., Gill 1982, p. 445 and 503-504).

As a first step toward testing the hypothesis that the wavelike signal on $10^{\circ}-20^{\circ} \mathrm{N}$ is a barotropic Rossby wave, we will use the barotropic Rossby wave dispersion relation to make a prediction for the orientation of the wave crests. Given the zonal wavenumber and frequency, the barotropic Rossby wave dispersion relationship gives a testable prediction for the meridional wavenumber and orientation of the wave crests. This test is chosen as a first step because it is less abstract than the more objective test that will be discussed shortly. Before using the dispersion relation to test the hypothesis that this variability is due to barotropic Rossby waves, we first need to determine what the appropriate expression for the dispersion relation of barotropic Rossby waves ought to be in the $10^{\circ}-20^{\circ} \mathrm{N}$ region, which is arguably less than one barotropic deformation radius from the equator. (Although definition of the barotropic deformation radius is problematic in this region where the Coriolis parameter varies substantially, it is expected to be on the order of $2000 \mathrm{~km}$.)

The linearized shallow water equations, ${ }^{3}$ written in Cartesian coordinates but not necessarily making an equatorial or midlatitude $\beta$-plane approximation, can be combined into a single equation for meridional velocity $v$ in the usual way (e.g., Gill 1982, 434-435),

$$
\left[\partial_{\mathrm{tt}}+f^{2}-c^{2}\left(\partial_{\mathrm{xx}}+\partial_{\mathrm{yy}}\right)\right] v_{t}-c^{2} f_{y} v_{x}=0
$$

where the subscripts represent partial differentiation, $\partial$ represents the partial derivative operator, $f$ is the Coriolis parameter, and $c$ is the gravity wave speed (equal to

\footnotetext{
${ }^{3}$ The $10^{\circ}-20^{\circ} \mathrm{N}$ region encompasses the westward North Equatorial Current, but the current is not expected to have a significant effect on the propagation of barotropic Rossby waves for the zonal wavenumbers and frequencies of interest here because the observed wave propagation speeds (of order $50 \mathrm{~cm} \mathrm{~s}^{-1}$ ) are much greater than plausible values of the mean barotropic flow speeds (a few $\mathrm{cm} \mathrm{s}^{-1}$ ). A posteriori support for assuming mean-flow effects are negligible will come from the good agreement between the observed wave propagation and the dispersion relation derived under this assumption.
} 
$\sqrt{g H}$, which is taken to be constant $\left.{ }^{4}\right)$. Fourier transforming Eq. (1) in longitude and time (i.e., in $x$ and $t$ ) or seeking a solution for $v$ of the form $v(y) e^{i(k x-\omega t)}$ and rearranging yields

$$
v_{\text {yy }}+\left(\frac{\omega^{2}}{c^{2}}-k^{2}-\frac{f_{y} k}{\omega}-\frac{f^{2}}{c^{2}}\right) v=0 .
$$

Because we are interested in the evolution of the waves and their dispersion relation and how these vary with latitude over a particular latitude range for a particular range of zonal wavenumbers and frequencies, we may simply substitute values of $\omega, k, f$, and $f_{y}$ corresponding to the ranges of interest to determine whether any terms in the square brackets of Eq. (2) are negligibly small compared to the others. The value of $c$ would be about $170-230 \mathrm{~m} \mathrm{~s}^{-1}$ for the water depths of $3000-5500 \mathrm{~m}$ seen in the eastern Pacific, so we take $c$ to be $200 \mathrm{~m} \mathrm{~s}^{-1}$. Given that we are interested in periods of about 33 days and wavelengths of about $13^{\circ}$ of longitude, nominal values of $\omega$ and $k$ (in radians) are $2.2 \times 10^{-6} \mathrm{~s}^{-1}$ and $4.4 \times$ $10^{-6} \mathrm{~m}^{-1}$. Over the latitude range of $10^{\circ}-20^{\circ} \mathrm{N}, f$ takes on values of $2.5-5.0 \times 10^{-5} \mathrm{~s}^{-1}$ and $f_{y}$ takes on values of 2.15-2.25 $\times 10^{-11} \mathrm{~s}^{-1} \mathrm{~m}^{-1}$. Conservatively using the larger value for $f$ and the smaller one for $f_{y}$, we find that the terms in the parentheses of Eq. (2) occur in the ratio of

$$
\frac{\omega^{2}}{c^{2}}: k^{2}: \frac{f_{y} k}{\omega}: \frac{f^{2}}{c^{2}}=6 \times 10^{-6}: 1: 2.2: 3 \times 10^{-3} .
$$

Clearly, the first and last terms in the parentheses of Eq. (2) are small in comparison to the others and will remain so over the entire range of latitudes, zonal wavenumbers, and frequencies of interest here. Because, in addition, $f_{y}$ varies by only about $6 \%$ over $20^{\circ} \mathrm{S}-20^{\circ} \mathrm{N}$, we can make an acceptably good approximation to Eq. (2) by neglecting the first and last terms in parentheses and treating $f_{y}$ as a constant, which yields a constant-coefficient differential equation that admits plane wave solutions with a sinusoidal meridional structure. Thus, the dispersion relation of barotropic Rossby waves at these latitudes,

\footnotetext{
${ }^{4}$ Topographic variations and the associated topographic $\beta$ effect have been neglected. For a meridional bottom slope $H_{y}$, the topographic $\beta$ effect is expected to be less important than the planetary $\beta$ effect when $\left|H_{y} f\right| /(H \beta)<1$ (e.g., LeBlond and Mysak 1978, p. 181). For the $10^{\circ}-20^{\circ} \mathrm{N}$ region of the eastern Pacific of interest here, this ratio is mostly less than 0.1 and is unusually small compared to its value at other locations (such as near midlatitude continental slopes where other barotropic Rossby waves have been observed), because, by comparison, the bottom slope is weak, $f$ is small, $H$ is large, and $\beta$ is large. Values in this region reach 0.5 only in isolated areas, near the Clarion Fracture Zone (near $16^{\circ} \mathrm{N}$, $140^{\circ} \mathrm{W}$ ) and isolated seamounts. Topographic effects may prove to be important in some respects, but they are left for future work.
}

zonal wavenumbers, and frequencies should be well approximated by

$$
\omega=\frac{-\beta k}{k^{2}+l^{2}},
$$

where $l$ is the meridional wavenumber and $\beta$ is $f_{y}$ evaluated at some particular latitude (we will use $15^{\circ} \mathrm{N}$ ). Equation (3) is the form of the barotropic Rossby wave dispersion relation familiar from quasigeostrophic theory (e.g., Pedlosky 1987, p. 379) and the one used by Cox (1980) in his argument that the wavelike variability seen away from the equatorial region in his GCM was due to radiation of barotropic Rossby waves from tropical instability waves. Although it was not initially obvious that the familiar dispersion relation in Eq. (3) would be a good approximation on $10^{\circ}-20^{\circ} \mathrm{N}$, it actually remains valid right to the equator, even for zonal wavelengths much larger than the ones of interest here.

If the wavelike variability seen on $10^{\circ}-20^{\circ} \mathrm{N}$ is due to radiation of barotropic Rossby waves from the tropical instability waves near the equator, we would expect the waves to have the same zonal wavelength and frequency as the tropical instability waves. At the same time, we would expect the barotropic Rossby wave dispersion relation [Eq. (3)] to be roughly satisfied, at least outside of the immediate vicinity of the forcing, giving a strong constraint on the meridional wavenumber depending on both zonal wavenumber and frequency. Furthermore, if the barotropic waves are a result of the instability near the equator and the wave energy is propagated to latitudes as high as $20^{\circ} \mathrm{N}$, we would expect the meridional component of the group velocity implied by the dispersion relation (i.e., $\partial w /$ $\partial l$ ) to be directed away from the equator. So, the strategy that will be used for an initial test of the hypothesis that barotropic Rossby waves are radiated northward from the equatorial instabilities will be to 1 ) estimate $k$ and $\omega$ for the tropical instability waves; 2 ) substitute those values into the dispersion relation to get a prediction for the meridional structure of the hypothetical barotropic Rossby waves that can be compared to the observed structure; and, 3) if that comparison is favorable, confirm that the energy propagation implied for those values of $k, l$, and $\omega$ is consistent with the hypothesis. Instead of trying to evaluate the value of $l$ in the filtered fields, we will use values of $k$ and $\omega$ estimated from the filtered field, together with the barotropic Rossby wave dispersion relation [Eq. (3)], to make a prediction for the wave crest slope $k / l$.

For the filtered field during late 1998, the dominant zonal wavenumber and frequency at $5^{\circ} \mathrm{N}$ were estimated to be $-4.97 \times 10^{-6} \mathrm{~m}^{-1}$ (11.5 $5^{\circ}$ zonal wavelength) and $2.31 \times 10^{-6} \mathrm{~s}^{-1}$ (31.5-day period), based on visual inspection of longitude-time plots of the filtered SSH (e.g., Fig. $2 \mathrm{~b}$; a more quantitative analysis will be presented 
(a)

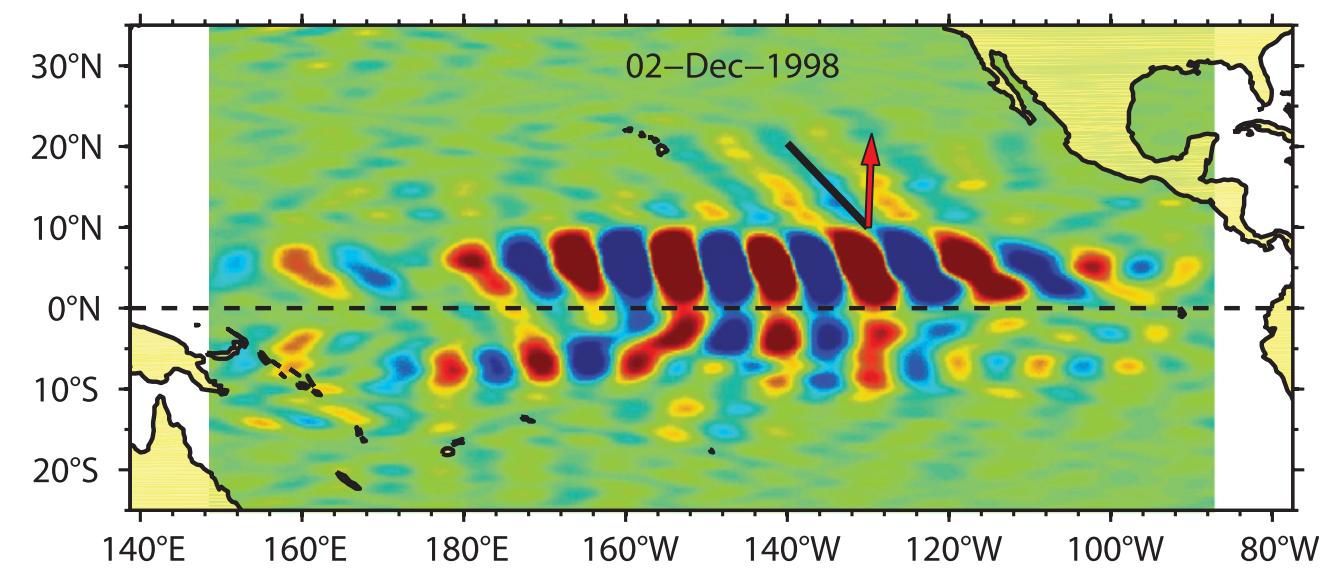

(b)

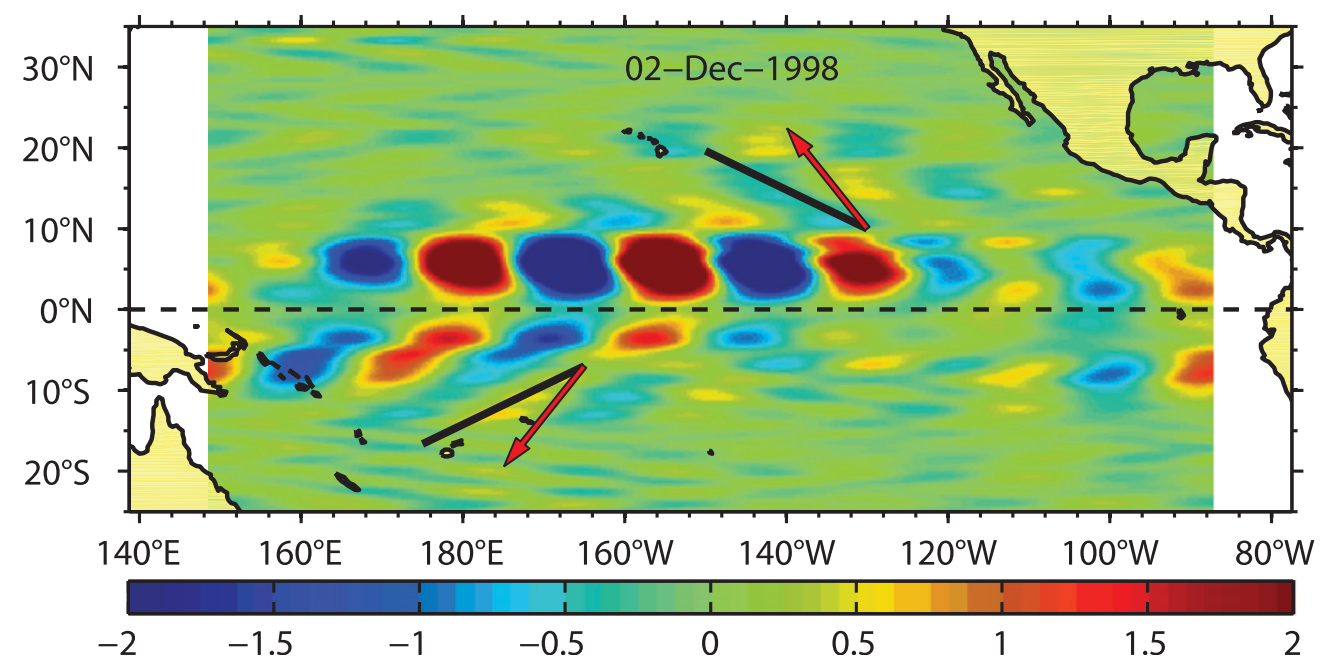

FIG. 7. Filtered SSH fields on 2 Dec 1998 for 2 different longitude-time passbands, with black lines indicating the orientation of wave crests expected from the barotropic Rossby wave dispersion relation and red arrows indicating the expected direction of group velocity. (a) The 32-day filtered SSH field (i.e., the filtered field shown in other figures; westward-propagating variability having wavelengths of $10^{\circ}-25^{\circ}$ of longitude and periods of 29-37 days), with the crest orientation and group velocity direction computed for an $11.5^{\circ}$ zonal wavelength and a 31.5-day period. (b) The 41-day filtered SSH field (westward-propagating variability having wavelengths of $21^{\circ}-31^{\circ}$ of longitude and periods of $34-52$ days), with the crest orientation and group velocity direction computed for a $25^{\circ}$ zonal wavelength and a 43 -day period. The barotropic Rossby wave dispersion relation seems to do a good job predicting the orientation of wave crests on $10^{\circ}-20^{\circ} \mathrm{N}, 120^{\circ}-150^{\circ} \mathrm{W}$.

shortly). The dispersion relation predicts a meridional wavenumber of $l= \pm 4.78 \times 10^{-6} \mathrm{~m}^{-1}\left(12.0^{\circ}\right.$ meridional wavelength). Choosing the negative value of $l$ yields a crest angle of about $46^{\circ}$ north of west (i.e., a crest slope of 1.04 degrees of latitude per degree of longitude), which is in good agreement with the orientation of the wave crests in the filtered field on $10^{\circ}-20^{\circ} \mathrm{N}$ (Fig. 7a). The group velocity vector implied by the dispersion relation for those values of $k, l$, and $\omega$ (Fig. 7a) is nearly due northward at $46 \mathrm{~cm} \mathrm{~s}^{-1}\left(c_{\mathrm{gx}}=2 \mathrm{~cm} \mathrm{~s}^{-1}, c_{\mathrm{gy}}=46 \mathrm{~cm} \mathrm{~s}^{-1}\right)$, consistent with the hypothesis that the waves are radiating northward.

The prediction of the wave crest orientation from the barotropic Rossby wave dispersion relation compares favorably with the filtered SSH field during the 1998/99 season. During other years, and even within a single TIW season, the TIWs and the wavelike signal on $10^{\circ}-20^{\circ} \mathrm{N}$ can have slightly different characteristics (e.g., Figs. 4, 5), and the process just undertaken can be repeated for other times with equally good agreement. However, the differences in wave properties, both observed and predicted, are not great because the spectrum of the filtered field is dominated by a small range of frequencies and zonal wavenumbers (Fig. 1).

We will now briefly consider a different bandpassfiltered version of the SSH field that has substantially different wavenumber-frequency content to yield a more dramatically different prediction for the orientation of the wave crests. A second bandpass filter was used to pass 
westward-propagating variability in SSH having zonal wavelengths of $21^{\circ}-31^{\circ}$ of longitude and periods of 34-52 days. Although this wavenumber-frequency band is not widely believed to be associated with TIWs, the filtered field shows some qualitative similarities to the filtered field that has been the focus so far. (To discuss the two filtered fields, we will refer to them by the period of the central frequency of the passbands, so the first one will be called the 32-day filtered field and the second one will be called the 41-day filtered field.) In particular, the amplitude of the variability near $5^{\circ} \mathrm{N}$ in the 41-day filtered field rises and falls annually with that in the 32-day filtered field, suggesting that the energy in this band is connected, possibly indirectly, to the instability of the equatorial current system. The 41-day filtered field also has wavelike signals on $10^{\circ}-20^{\circ} \mathrm{N}$ with wave crests that tilt westward with increasing distance from the equator.

The 41-day filtered field is shown in Fig. 7b for 2 December 1998, the same time shown for the 32-day filtered field in Fig. 7a. For this time period, the dominant zonal wavenumber and frequency in the 41-day filtered field at $5^{\circ} \mathrm{N}$ were estimated to be $-2.26 \times 10^{-6} \mathrm{~m}^{-1}\left(25^{\circ}\right.$ zonal wavelength) and $1.69 \times 10^{-6} \mathrm{~s}^{-1}$ (43-day period), which yields a prediction for the meridional wavenumber of $l=-4.74 \times 10^{-6} \mathrm{~m}^{-1}$ (wavelength of $12^{\circ}$ ) and a crest angle $26^{\circ}$ north of west. (We have again chosen the negative value of $l$.) The predicted crest orientation seems to agree with the observed orientation over $10^{\circ}-20^{\circ} \mathrm{N}$ (Fig. 7b). The group velocity vector implied by the dispersion relation for those values of $k, l$, and $\omega$ is roughly to the northwest at $80 \mathrm{~cm} \mathrm{~s}^{-1}\left(c_{\mathrm{gx}}=-50 \mathrm{~cm} \mathrm{~s}^{-1}\right.$, $\left.c_{\mathrm{gy}}=62 \mathrm{~cm} \mathrm{~s}^{-1}\right)$. Interestingly, there is also a suggestion of southward radiation at these wavenumbers and frequencies south of the equator in the western Pacific (Fig. 7b). The filtered field shown in Fig. 7b looks noisy, raising a legitimate question about how many lines of arbitrary slope could be drawn on the field to yield an apparently good fit. We thus now turn our attention to a more objective test of the hypothesis that reduces the danger of "successfully" fitting a line to noise.

The hypothesis that the TIWs near the equator radiate barotropic Rossby waves to the north can be tested more objectively in the spectral domain using coherence phase estimates like the one shown in Fig. 6b. Because the phase $\theta$ of a plane wave is defined as $\theta \equiv k x+l y-\omega t$, the rate of change of phase with latitude is the meridional wavenumber, so the dispersion relation can be used to make a prediction for the phase structure as a function of latitude for each zonal-wavenumber-frequency band. The basic approach will be to compute the coherence phase between $5^{\circ} \mathrm{N}$ and each other latitude, which will yield estimates of the phase relative to $5^{\circ} \mathrm{N}$ as a function of latitude, zonal wavenumber, and frequency that can be compared to predictions made from the dispersion relation. This approach to testing the hypothesis has a number of advantages over the approach just used for the filtered fields: 1) zonal wavenumber and frequency are independent variables in the spectral calculations, so there is little subjectivity in choosing values of $k$ and $\omega$ for substitution into the dispersion relation; 2) by using the coherence phase relative to $5^{\circ} \mathrm{N}$ and only examining the estimates at latitudes where the coherence amplitude is statistically significant, we are assured that the signal we are examining is at least coherent with and probably causally connected to the larger-amplitude variability on $5^{\circ} \mathrm{N}$; and, 3 ) perhaps most importantly, we can examine many different combinations of zonal wavenumber and frequency, which will yield different predictions for the meridional structure of the waves and provide a more stringent test of the hypothesis that this variability on $10^{\circ}-20^{\circ} \mathrm{N}$ obeys the dispersion relation of barotropic Rossby waves.

In computing the coherence phase against $5^{\circ} \mathrm{N}$ at each latitude, we obtain estimates at all of the zonal wavenumbers and frequencies that are possible within the confines of the data record and analysis, including ones where barotropic Rossby waves are not expected (e.g., eastward-propagating wavenumbers). Some semiobjective criterion is needed for selecting zonal wavenumbers and frequencies to include in the hypothesis test. We will show results only for the westward-propagating zonalwavenumber-frequency bands corresponding to wavelengths of $6.7^{\circ}-50^{\circ}$ of longitude that have variability coherent with that at $5^{\circ} \mathrm{N}$ (at $95 \%$ confidence or better) on at least half of the latitudes on $10^{\circ}-20^{\circ} \mathrm{N}$ (i.e., on at least 10 of the 20 half-degree latitude increments between $10.5^{\circ}$ and $20^{\circ} \mathrm{N}$, inclusive). There were 18 zonal-wavenumberfrequency bands meeting that criterion (Fig. 8). These bands span zonal wavelengths of $9.2^{\circ}-22.5^{\circ}$ of longitude and periods of 25.5-38.0 days.

A basic, but important, conclusion to be drawn from Fig. 8 is that there is variability on $10^{\circ}-20^{\circ} \mathrm{N}$ that is significantly coherent with that at $5^{\circ} \mathrm{N}$ in almost all of the zonal-wavenumber-frequency bands that one might associate with the 33-day TIWs seen in SSH. The coherence phase and gain relative to $5^{\circ} \mathrm{N}$ (Figs. 9, 10), for which estimates are shown only at latitudes where the coherence amplitude was judged statistically significant, also makes clear that each one of these bands has variability coherent with that at $5^{\circ} \mathrm{N}$ at meridional distances of $1600 \mathrm{~km}$ or more. These meridional profiles of coherence gain and phase can be tentatively interpreted as reflecting meridionally coherent modes of SSH variability, though one can easily imagine situations where this interpretation would be wrong (i.e., because two records that are coherent with a third are not necessarily coherent with each other). With attention limited to $10^{\circ} \mathrm{S}-10^{\circ} \mathrm{N}$, Farrar (2008) made this 


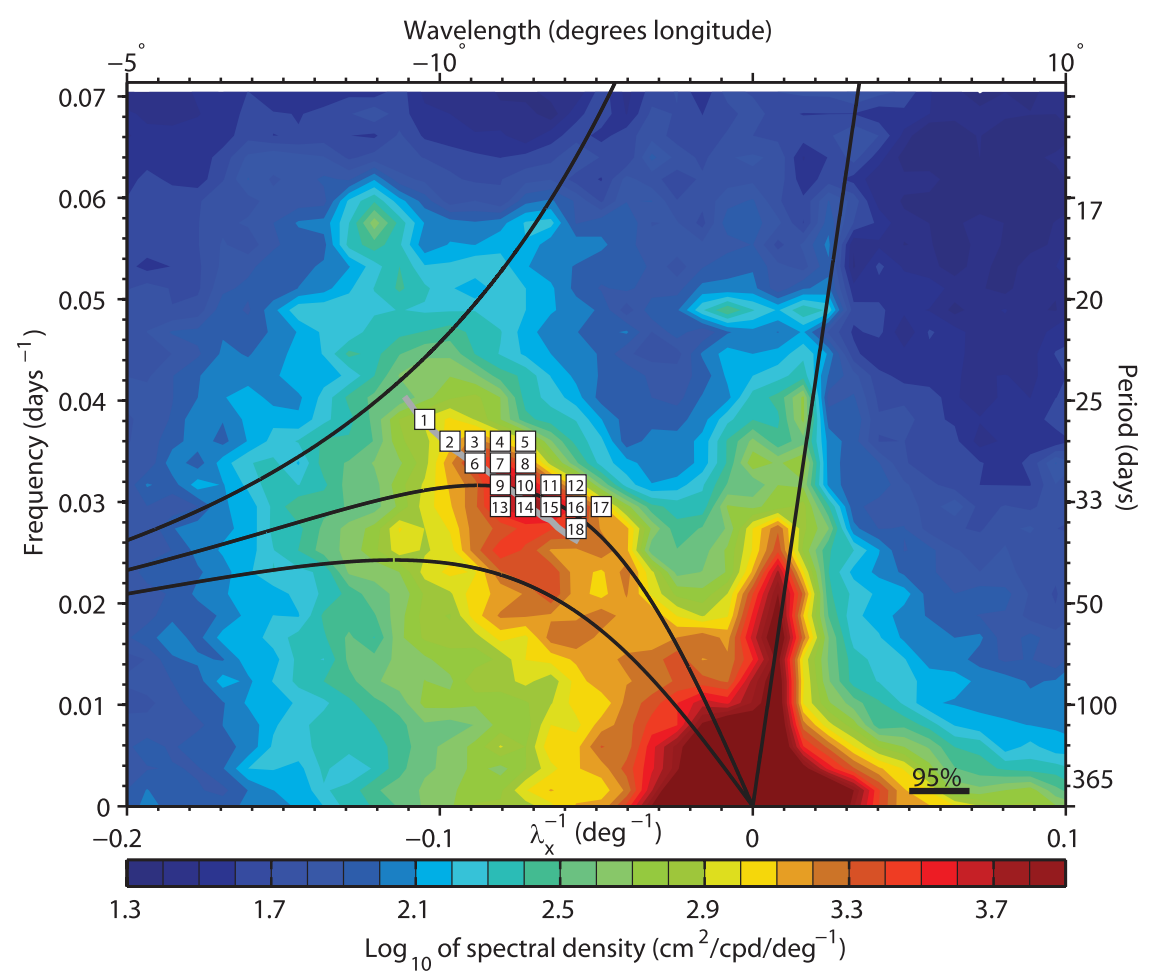

FIG. 8. Zonal-wavenumber-frequency spectrum of SSH, averaged over $7^{\circ} \mathrm{S}-7^{\circ} \mathrm{N}$ (as in Fig. 1), with white squares marking the zonal-wavenumber-frequency points exhibiting significant coherence of SSH between $5^{\circ} \mathrm{N}$ and at least half of the latitudes on $10^{\circ}-20^{\circ} \mathrm{N}$. The numbers on the squares are to aid interpretation of Figs. 9-12. The four black curves are the dispersion curves of first-baroclinic-mode linear equatorial waves. A more realistic theoretical dispersion curve for the TIWs, derived by Lyman et al. (2005) from a linear stability analysis, is indicated by a thick gray curve (largely obscured by the white squares). At essentially all of the zonal wavenumbers and frequencies associated with the 33-day TIW spectral peak, there is SSH variability on $10^{\circ}-20^{\circ} \mathrm{N}$ coherent with that at $5^{\circ} \mathrm{N}$.

interpretation of the relative gain and phase in one of these wavenumber-frequency bands (i.e., the one shown in Fig. 6) and others, finding reasonably good agreement with the theoretical prediction of Lyman et al. (2005) and similarly good agreement of other such modes with theoretical expectations.

The zonal wavenumber and frequency for each meridional profile of coherence phase was used with the dispersion relation to make a prediction for meridional wavenumber, $l=\partial \theta / \partial y$, which gives a prediction for the variation of phase with latitude ${ }^{5}$ (red lines in Fig. 9). The

\footnotetext{
${ }^{5}$ Note that the phase convention used for the coherence phase calculations plotted in Fig. 9 (and Fig. 6b) is slightly different than the phase convention commonly used in theoretical work [including Eqs. (2) and (3) and the definition of $\theta$ given in the text]. Doing this made the cross-spectral calculations somewhat simpler to code and yields phase estimates consistent with related prior work (Lyman et al. 2005; Farrar 2008). Under the phase convention used in Fig. 9, a linear increase of phase with latitude corresponds to a negative meridional wavenumber, and the theoretical predictions (red lines) are plotted using the appropriate phase convention.
}

agreement between the variation of phase with latitude predicted from the barotropic Rossby wave dispersion relation and the observational estimate is remarkable (Fig. 9). Only a small fraction of the phase estimates at latitudes on $10^{\circ}-25^{\circ} \mathrm{N}$ appear to be inconsistent with Rossby wave dispersion. (About $4.7 \%$ of the phase estimates at individual latitudes on $10^{\circ}-25^{\circ} \mathrm{N}$ have $95 \%$ confidence intervals that do not encompass the Rossby wave prediction.)

An attempt was made to condense the information in Fig. 9 by performing a least squares fit of a line to the phase estimates over $10.5^{\circ}-20^{\circ} \mathrm{N}$. The slope of that line, which should represent the meridional wavenumber, can then be used for comparisons to predictions from the barotropic Rossby wave dispersion relation. Using the slope of a least squares fitted line is a tough test of the hypothesis and is perhaps not the best way of estimating the meridional wavenumber from the phase because the nature of the least squares method can make a single data point lying far off the trend modify the slope of the fitted line substantially. A comparison of the meridional wavenumber 

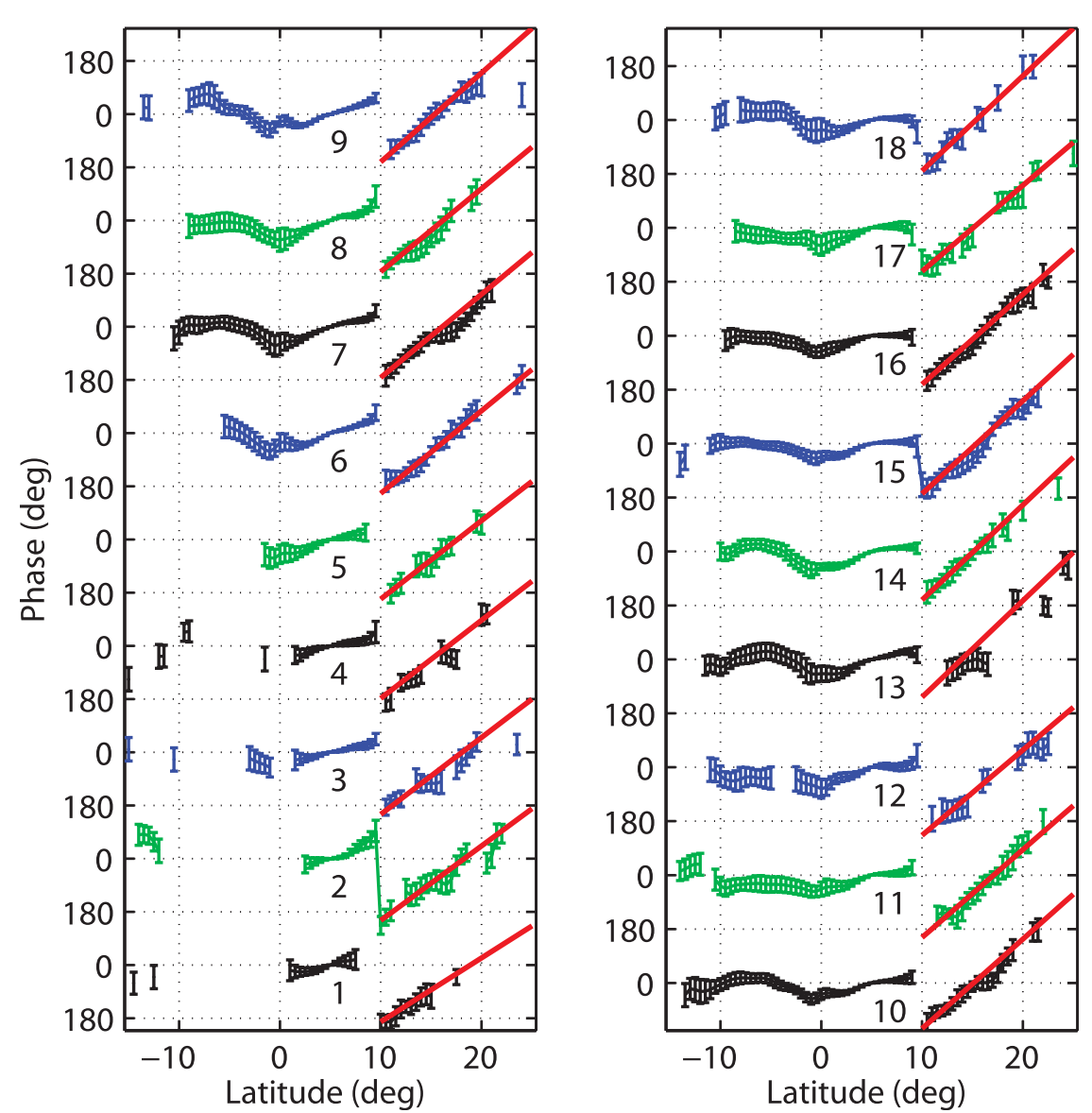

FIG. 9. Meridional profiles of phase, relative to $5^{\circ} \mathrm{N}$, for zonal-wavenumber-frequency bands meeting the criterion described in the text (involving significant coherence of variability on $10^{\circ}-$ $20^{\circ} \mathrm{N}$ with that at $5^{\circ} \mathrm{N}$ ). Phase increases upward, such that larger values lead in time or westward longitude. The red lines indicate the variation of phase with latitude expected from the barotropic Rossby wave dispersion relation for the zonal wavenumber and frequency of each estimate. The numbers by each profile near $5^{\circ} \mathrm{N}$ correspond to the points shown in Fig. 8, and each profile is offset by $360^{\circ}$. Error bars are $95 \%$ confidence limits on phase, and an error bar is shown if coherence amplitude versus $5^{\circ} \mathrm{N}$ is significant at $>95 \%$ confidence.

estimated by the fit to that from the dispersion relation (Fig. 11) yields reasonably good agreement, with a correlation coefficient of 0.80 . (A correlation coefficient of 0.59 would be considered significantly different from zero at $99 \%$ confidence; e.g., Emery and Thomson 2001, p. 585.) The meridional wavenumbers estimated from the fit correspond to wavelengths of $10.8^{\circ}-16.5^{\circ}$ of latitude, and this relatively small range of meridional wavenumbers (discussed in appendix B) gives the scatterplot a somewhat unimpressive appearance. If we instead compare the observed and predicted crest orientations given by arc$\tan (k / l)$ (Fig. 12; expressed as an angle north of west), which takes account of the range of zonal wavenumbers at which these meridional wavenumbers are found, we obtain a more impressive linear relationship, with a correlation coefficient of 0.96. Appendix B discusses dynamical and statistical reasons for this difference between the correlation coefficients in the comparisons of observed and predicted meridional wavenumbers and wave crest angles.

\section{Discussion}

The primary conclusions to be drawn from the material presented here are 1) there is SSH variability on $10^{\circ}-20^{\circ} \mathrm{N}$ in the eastern Pacific that is coherent with variability associated with the energetic tropical instability waves found closer to the equator and 2) this variability on $10^{\circ}-$ $20^{\circ} \mathrm{N}$ propagates in a manner consistent with expectations for barotropic Rossby waves. Taken together, these facts suggest that barotropic Rossby waves are being radiated from the instabilities.

These conclusions seem robust for the 18 zonalwavenumber-frequency bands identified in Fig. 8 (periods of 26-38 days and zonal wavelengths of $9^{\circ}-23^{\circ}$ of longitude), 

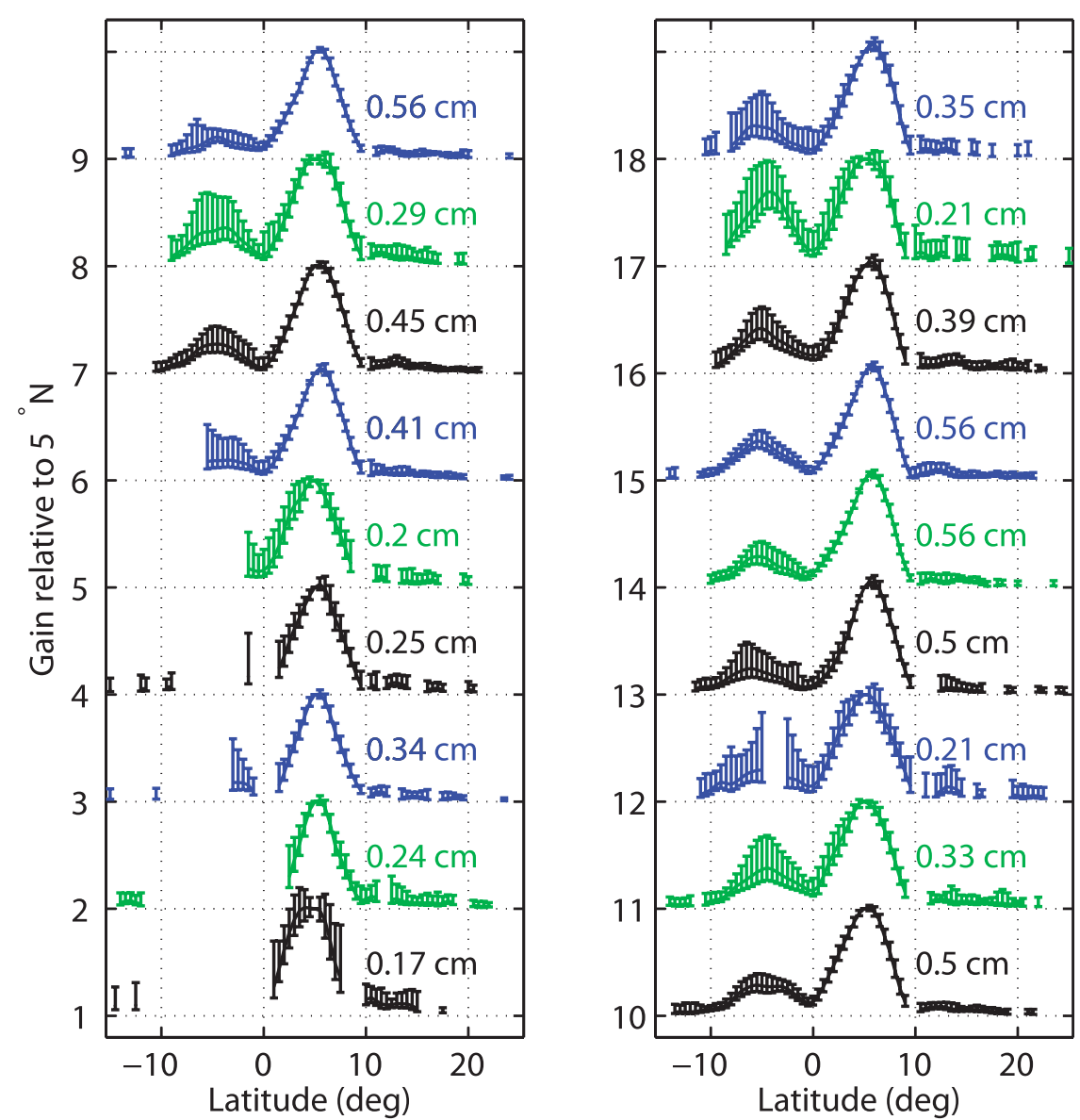

FIG. 10. Meridional profiles of gain, relative to $5^{\circ} \mathrm{N}$, for zonal-wavenumber-frequency bands meeting the criterion described in the text (involving significant coherence of variability on $10^{\circ}-20^{\circ} \mathrm{N}$ with that at $5^{\circ} \mathrm{N}$ ). Each profile has a value of one at $5^{\circ} \mathrm{N}$, but successive profiles have been offset for display. In addition to giving a scale for the gain, the numbers on the left axis of each panel correspond to the numbers labeling wavenumber-frequency points in Fig. 8. The color-coded number next to each profile near $10^{\circ} \mathrm{N}$ gives the RMS amplitude at $5^{\circ} \mathrm{N}$ within that band, to allow comparison of the relative SSH amplitude of the various bands. (The RMS amplitudes are only meaningful relative to one another, because the magnitudes are dependent on the bandwidth of the spectral estimates.) Error bars are $95 \%$ confidence limits on the gain, and an error bar is shown if coherence amplitude versus $5^{\circ} \mathrm{N}$ is significant at $>95 \%$ confidence.

but it should be noted that the criterion used to select those particular bands for examination was somewhat arbitrary (though objective). Radiation of barotropic Rossby waves from TIWs probably occurs at times over an even wider range of zonal wavenumbers and frequencies (e.g., Fig. 7b). Although TIWs in the Atlantic Ocean were not examined here, the known analogies between Pacific and Atlantic TIWs are strong enough that it seems reasonable to expect that Atlantic TIWs should also radiate barotropic Rossby waves.

No strong evidence was found for southward radiation of barotropic Rossby waves into the Southern Hemisphere (southward radiation would have an appearance similar to northward radiation but as a "mirror image" about the equator). Still, there are some suggestive signs of southward radiation (e.g., 1998 panel of Fig. 4, August and October panels of Fig. 5, and Fig. 7b). The lack of clear southward radiation may simply be a signal to noise issue, because the Southern Hemisphere expression of TIWs is several times weaker than the Northern Hemisphere one; if southward-radiating barotropic waves are proportionately weaker, they are likely below the detection threshold of the merged altimetry product. Or the lack of barotropic radiation into the Southern Hemisphere could be for a good dynamical reason, such as differences in the bottom topography. One is also led to wonder, could 


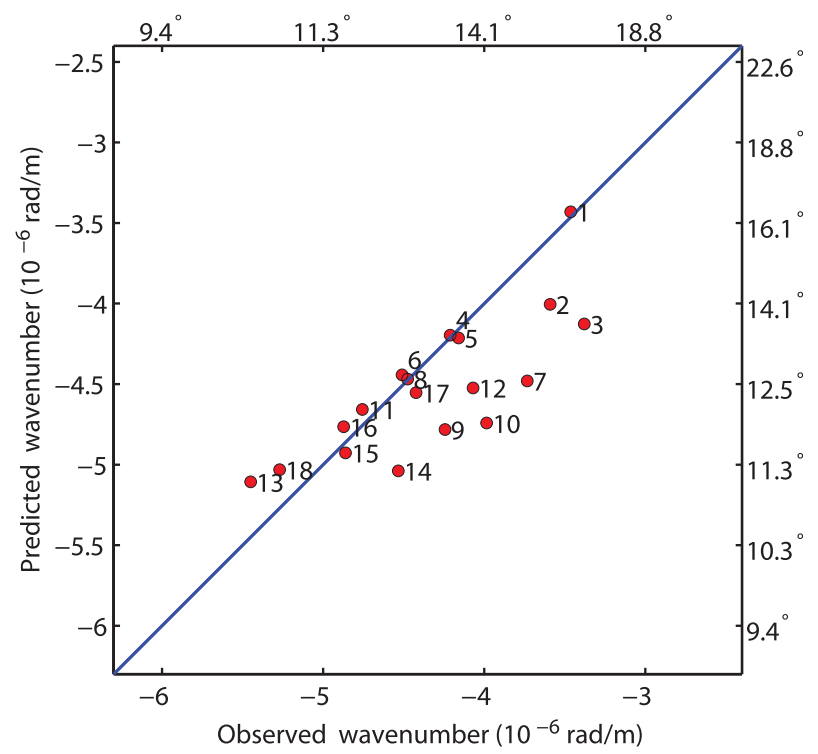

FIG. 11. Comparison of meridional wavenumber from least squares fit to the phase profiles in Fig. 9 over $10^{\circ}-20^{\circ} \mathrm{N}$ (horizontal axis) to the meridional wavenumber expected from the barotropic Rossby wave dispersion relation (vertical axis). The numbers in the plot correspond to the zonal-wavenumber-frequency points shown in Fig. 8. The corresponding meridional wavelengths (in degrees of latitude) are shown on the top and right axes. The correlation coefficient is 0.80 .

the TIW disturbances at $5^{\circ} \mathrm{N}$ radiate barotropic Rossby waves southward? With a better understanding of the dynamics responsible for radiation of barotropic Rossby waves from near-equatorial instabilities, we could address these questions and others.

The remainder of this paper will discuss possible shortcomings and complications with the interpretation of the variability as barotropic Rossby waves and offer speculation on the causes and consequences of these waves.

\section{a. Comments on the analysis and interpretation}

The inference that these are barotropic Rossby waves is based on the fact that the variability obeys the barotropic Rossby wave dispersion relation; although the uncertainty of the analysis here is large enough that any more complicated interpretation would be unwarranted, more detailed observations of the phenomenon may require more nuanced interpretations. It would not be surprising if the waves experience some kind of interaction with topography, which might modify propagation and dispersion in subtle ways not noticed here. The SSH observations themselves cannot tell us the vertical structure of velocity within the water column, and future studies using, for example, in situ velocity measurements or GCMs may indicate that the variability is not purely barotropic. (Perhaps the real surprise is that the

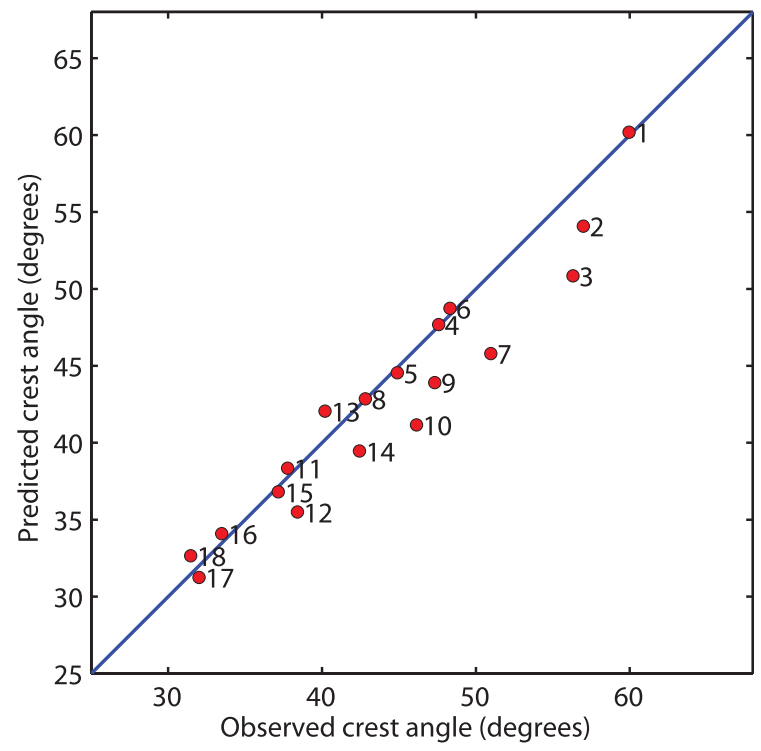

FIG. 12. Comparison of observed wave crest orientation (horizontal axis), derived from a least squares fit to the phase profiles in Fig. 9, to the crest orientation expected from the barotropic Rossby wave dispersion relation given the zonal wavenumber and frequency of each estimate. The crest orientations are expressed as an angle north of west. The numbers in the plot correspond to the zonal-wavenumber-frequency points shown in Fig. 8. The correlation coefficient is 0.96 .

simple interpretation offered here can explain as much of the observed variability as it does.)

Caution is required regarding the data product and analysis techniques used here. The spectral analysis and filtering techniques used here have well known limitations (e.g., inevitable spectral leakage in longitude-zonal wavenumber and time-frequency), and the analysis presumes that the zonal wavenumber and frequency remain constant along a ray, something that is unlikely to be true if the waves undergo refraction because of the topographic $\beta$ effect (e.g., Bower and Hogg 1992). Caution must also be used in interpretation of spectra from gridded satellite altimetry observations, because the potential for sampling artifacts, mapping errors, or other systematic errors, and especially how these manifest in spectral estimates, is poorly understood. Despite the limitations of the data and analysis, the interpretation that barotropic Rossby waves are being radiated from tropical instability waves has strong support, and it is hard to imagine another plausible interpretation of these observations that is substantially different.

\section{b. Speculation on causes}

The inference that the barotropic Rossby waves are related to the TIWs suggests two classes of generation mechanisms for them: either the large-amplitude TIWs cause them or the instability process generates the TIWs 
and the barotropic Rossby waves together. In the first class, the TIWs may cause the barotropic waves through nonlinear interactions, and the barotropic waves would be viewed as an indirect, secondary effect of the instability of the equatorial currents. In this case, one might interpret the situation as one in which the evolution of the TIWs to finite amplitude leads to "barotropization," or a transfer of energy from baroclinic motions to barotropic ones via nonlinear wave-wave interactions, whether conceived of as wave-triad interactions (e.g., Fu and Flierl 1980) or as a turbulent cascade (e.g., Smith and Vallis 2001). The observed phase locking of the barotropic Rossby waves and the baroclinic TIWs would not necessarily be expected if the barotropic Rossby waves are a result of nonlinear interactions involving the TIWs.

In the second class, the barotropic Rossby waves would be an intrinsic aspect of the instability process, and, in a linear stability analysis, one would expect the barotropic waves to appear as part of the unstable TIW mode. The observed phase locking of the barotropic Rossby waves and the baroclinic TIWs would follow trivially from their being part of the same mode. Although linear stability models of the equatorial current system can do a good job of predicting some of the observed properties of TIWs (e.g., Fig. 6; Lyman et al. 2005; Farrar 2008), they have apparently never predicted radiating barotropic variability, an outcome essentially guaranteed by the use of zonalchannel configurations in which wall boundary conditions are applied somewhere in the tropics (W. Smyth 2008, personal communication; e.g., Philander 1978; Lyman et al. 2005). Moreover, most linear stability analyses of TIWs have used a truncated vertical structure that excludes the possibility of barotropic variability (e.g., Philander 1978; Lyman et al. 2005). However, there is at least one tantalizing exception in which a linear stability analysis of TIWs showed barotropic variability: the most unstable mode of the continuously stratified model of Proehl (1996) showed barotropic variability on $7^{\circ}-10^{\circ} \mathrm{N}$ (and $7^{\circ}-10^{\circ} \mathrm{S}$ ) phase locked with the stronger baroclinic variability near $5^{\circ} \mathrm{N}$ (Fig. 11 of Proehl 1996). However, Proehl (1996) mentioned this only in passing, and there were walls at $10^{\circ} \mathrm{N}$ and $10^{\circ} \mathrm{S}$, so it is not clear whether the variability would resemble that discussed here if different boundary conditions had been used. Linear stability analyses of other unstable currents, when using boundary conditions that permit radiation, have found radiating unstable modes (e.g., Talley 1983b; Sutherland et al. 1994; Kamenkovich and Pedlosky 1996; Sun et al. 1998; Hristova et al. 2008).

The work of Talley $(1983 a, b)$ on radiation from unstable midlatitude currents seems especially germane to the observations presented here. In the context of a linear stability analysis, she found that radiation into the far field occurs whenever the zonal wavenumber and frequency of the instabilities can match those of a free wave mode in the region adjacent to the unstable current and that "the vertical structure of the radiated waves depended entirely" on which vertical modes could satisfy that condition (Talley 1983b). Excluding substantial modification of the dispersion properties of baroclinic waves by meanflow or topographic effects, barotropic Rossby waves are the only free waves that can exist north of $10^{\circ} \mathrm{N}$ at TIW zonal wavenumbers and frequencies. Another relevant finding that bears on interpretation of the results here is that, although radiating instabilities can propagate energy far from the unstable current, the radiation can be weakly trapped to the unstable current, leading to a slow decay of the amplitude of the radiating variability away from the unstable current (Talley 1983b).

Although it seems promising that the generation of the barotropic Rossby waves could be understood as part of the (linear) instability process, the TIWs are nonlinear (e.g., Kennan and Flament 2000) and finite-amplitude effects may be important as well. The two classes of generation mechanisms just discussed are closely analogous to the "primary" and "secondary" generation mechanisms discussed by Sutherland et al. (1994) for radiation of internal gravity waves from atmospheric instabilities. Sutherland et al. (1994) discussed cases in which radiating internal gravity waves were excited as an intrinsic part of the linear instability ("primary generation") and other cases in which radiating internal gravity waves were excited through nonlinear interactions ("secondary generation"). This suggests that either or both of the mechanisms could be active here. However, barotropic Rossby waves resulting from nonlinear interactions could have different zonal wavenumbers and frequencies than the TIWs responsible for them and thus might not be detected by the cross-spectral analysis used here, which is predisposed to detection of linear relationships within a single wavenumber-frequency band.

A conspicuous feature of the filtered fields (e.g., Fig. 4) and the meridional profiles of phase (Fig. 9) is the abrupt phase change seen moving northward across $10^{\circ} \mathrm{N}$. This phase change across $10^{\circ} \mathrm{N}$ has values near $180^{\circ}$ in some of the most energetic wavenumber-frequency bands (e.g., bands labeled as numbers 9, 10, 14, and 15 in Fig. 9), whereas there are other bands with more continuous phase variations across $10^{\circ} \mathrm{N}$ (e.g., band numbers 2 and 8 in Fig. 9; note that the phase "jump" in band 2 of Fig. 9 is about $360^{\circ}$ : i.e., about $0^{\circ}$ ). It is not clear why some bands show an abrupt phase jump and others do not, but an explanation of the generation of the barotropic waves ought to be able to explain this feature of the observations.

Nonetheless, we are now in a position to attempt to rationalize the existence of the meridional phase discontinuity 
seen near $10^{\circ} \mathrm{N}$. Variability resembling that seen here has been seen in previous work with GCMs, in both the barotropic streamfunction (Fig. 12 of Cox 1980) and ocean bottom pressure (Fig. 2b of Song and Zlotnicki 2004); both of these quantities are expected to effectively "filter out" baroclinic variability. Remarkably, these fields do not show a meridional phase jump near $10^{\circ} \mathrm{N}$ (especially see Song and Zlotnicki 2004). SSH, on the other hand, is expected to prominently reflect both barotropic and baroclinic variability. The TIWs near $5^{\circ} \mathrm{N}$ are known to be a highly baroclinic phenomenon, with strong subsurface temperature signals (e.g., McPhaden 1996; Lyman et al. 2007) and velocity signals that are strongly vertically sheared (e.g., Kennan and Flament 2000), and theoretical models that treat TIWs as a purely baroclinic phenomenon (e.g., Lyman et al. 2005) can do a fine job explaining their most prominent features (e.g., Figs. 6a,b). The amplitude of the TIW mode in the purely baroclinic model of Lyman et al. (2005) decays very rapidly to zero moving northward toward $10^{\circ} \mathrm{N}$ (Fig. 6a). Thus, a plausible interpretation of the phase jump seen here in SSH is that it is simply a result of the superposition of equatorially trapped baroclinic TIWs that have a large SSH amplitude that decreases to zero near $10^{\circ} \mathrm{N}$, together with radiating barotropic Rossby waves that have a much smaller but less meridionally variable SSH signal. The barotropic Rossby waves at $\sim 30$-day periods are obscured by the stronger baroclinic variability near the equator and can be seen only at higher latitudes where the baroclinic variability does not dominate the SSH signal. In this scenario, having a particular phase jump near $10^{\circ} \mathrm{N}$ would simply reflect the fact that the SSH signals of the barotropic and baroclinic fluctuations have a particular phase relationship. This is a phenomenological and somewhat speculative description of the relationship between the baroclinic TIWs and the radiating barotropic Rossby waves; a more mechanistic description that could explain why the baroclinic and barotropic fluctuations occur with a particular phase arrangement would be more satisfying.

\section{c. Speculation on consequences and significance}

Because the waves apparently draw their energy and momentum from either the TIWs or the equatorial current system, it is natural to wonder whether the waves play a role in the energy and momentum balance of either. Cox (1980) examined the energy balance and fluxes in his GCM simulations and suggested that the barotropic waves do not play a significant role in the energy budget after finding that (the zonally averaged) meridional radiation was small in comparison to the vertical radiation associated with baroclinic equatorial waves.

Even less can be said about the role of the waves in the momentum balance. The waves are associated with a

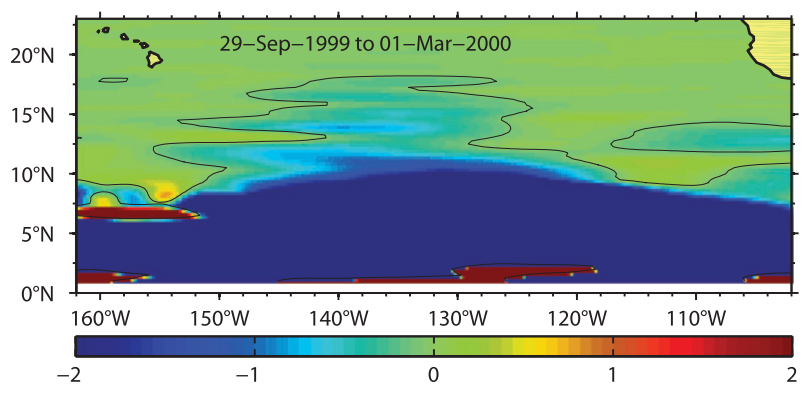

FIG. 13. Reynolds stress $\left(\left\langle u^{\prime} v^{\prime}\right\rangle\right)$ computed from the geostrophic velocity of the filtered field over a 5-month period (29 Sep 1999 1 Mar 2000), in units of $10^{-4} \mathrm{~m}^{2} \mathrm{~s}^{-2}$. The color scale is saturated south of about $10^{\circ} \mathrm{N}$. A broad patch of negative values, delineated by a black contour at $-10^{-5} \mathrm{~m}^{2} \mathrm{~s}^{-2}$, is present near $10^{\circ}-20^{\circ} \mathrm{N}$, $125^{\circ}-145^{\circ} \mathrm{W}$, as expected in the presence of northward-radiating Rossby waves.

northward flux of westward momentum, as can be seen from estimation of the Reynolds stress $\left(\left\langle u^{\prime} v^{\prime}\right\rangle\right)$ from the geostrophic flow of the filtered field (Fig. 13) or simple theoretical reasoning. [The time- or space-averaged Reynolds stress of a plane, nondivergent Rossby wave is $\left\langle u^{\prime} v^{\prime}\right\rangle=-k \lg ^{2} \eta^{2} /\left(2 f^{2}\right)$, where $\eta$ is the sea level displacement amplitude; because the zonal wavenumber $k$ is negative definite and the meridional wavenumber $l$ is negative, the barotropic waves are associated with a negative Reynolds stress.] Because the wave amplitude and Reynolds stress decay moving northward, there should be an associated momentum flux divergence. Assuming that the SSH amplitude is $1 \mathrm{~cm}$ at $15^{\circ} \mathrm{N}$ (e.g., Figs. 3-5) and that the zonal and meridional wavenumbers are $-5 \times$ $10^{-6} \mathrm{~m}^{-1}$, the momentum flux (i.e., $\left\langle u^{\prime} v^{\prime}\right\rangle$ ) would be about $-10^{-4} \mathrm{~m}^{2} \mathrm{~s}^{-2}$. (Fig. 13 suggests the Reynolds stress is slightly smaller in a 5-month average.) If the flux decreases to zero over a meridional length scale of $5^{\circ}$ of latitude, the flux divergence would be about $1.5 \times$ $10^{-10} \mathrm{~m} \mathrm{~s}^{-2}$. Guessing the possible effect of this on the flow would require making an assumption about the dynamical balance: not being able to do this with any confidence, we note here that, if the momentum flux divergence served to balance linear bottom drag on the low-frequency barotropic flow $\left(\left\langle u^{\prime} v_{y}{ }^{\prime}\right\rangle_{y}=-r\langle u\rangle\right)$, the momentum flux divergence would be sufficient to maintain a westward low-frequency barotropic flow of 0.1$4 \mathrm{~cm} \mathrm{~s}^{-1}$ in the presence of bottom drag, where the range comes from uncertainty in the drag coefficient $r$, which was chosen following Warren et al. (2002). This calculation is likely not good to an order of magnitude and is meant only to suggest that the decaying waves may drive other motions. It is not clear whether the small-scale meridional variations of Reynolds stress seen north of $10^{\circ} \mathrm{N}$ in Fig. 13 are significant, but, if they are, they could also drive more appreciable flows. Better estimates of the 
role of the barotropic waves in the energy and momentum balances of the tropics and subtropics are of course possible and desirable.

Even if the barotropic waves do not have a substantial effect on TIWs, the equatorial current system, or the subtropical gyre, there are still several reasons the waves are of interest. One is that there are few known examples of barotropic Rossby waves, especially in the altimetry record, and we do not fully understand their contribution to oceanic variability. Wunsch (1997) suggests that barotropic variability may account for a major fraction of the water-column kinetic energy, roughly as much as the first baroclinic mode does. Here is a readily observable example of barotropic Rossby waves. Further study of these waves may confirm that they are also an example of energy transfer to larger vertical scales, a step in the process referred to as the "inverse cascade." Given that the situation here does not appear to be fully turbulent, a mechanistic understanding of the instability and the excitation of other scales seems attainable, and such understanding might yield insights into more complicated situations found elsewhere in the world's oceans.

Acknowledgments. Ted Durland and Dudley Chelton provided insightful discussion on this work over a couple of years, and discussions with Durland were especially helpful in formulating the treatment surrounding Eqs. (1)-(3). Durland, Chelton, Jim Price, Bruce Warren, and two anonymous reviewers provided helpful comments on the manuscript. Discussions with Bill Smyth, Roland DeSoeke, Roger Samelson, Ken Brink, Kurt Polzin, Carl Wunsch, Joe Pedlosky, and Mike Spall also helped shape this paper. The altimeter product was produced by SSALTO/DUACS and distributed by AVISO, with support from CNES (http://www.aviso.oceanobs.com/ duacs/). I appreciate the efforts of the many scientists, engineers, and others who have developed satellite altimetry over the preceding decades, to the point that I am able to use it to examine a sea level signal on the order of a centimeter. Funding for this research came from WHOI's Tropical Research Initiative, the Charles D. Hollister Fund for Assistant Scientist Support, the John E. and Anne W. Sawyer Endowed Fund in Special Support of Scientific Staff, and Grant OCE-0845150 from the National Science Foundation.

\section{APPENDIX A}

\section{Discussion of Noise in the Filtered Field}

If there were an estimate of the spectrum of the noise due to measurement, sampling, and mapping errors, it would be a simple matter to estimate the variance of the noise in the filter passband. Not having such an estimate, we can at least get a sense of the possible noise amplitude within the passband by supposing that the noise is white. Because the variance of white noise is uniformly distributed in frequency and wavenumber, the variance of the noise within the passband is proportional to the fraction of the total number of wavenumber-frequency bands that fall within the passband.

There are 561 wavenumber-frequency bands within the passband. ${ }^{6}$ Estimation of the total number of wavenumberfrequency bands is a more subtle issue; the effective longitude-time resolution of the gridded AVISO "reference" product (i.e., the one using data from only two altimeters at a given time, as opposed to the product used here, which uses up to five altimeters) is believed to be about $2^{\circ}$ by 10 days (Ducet et al. 2000; Chelton et al. 2011). The effective longitude-time resolution will set the effective Nyquist wavenumber-frequency for the resolved part of the spectrum. The issue is that the smoothing inherent in the AVISO data preprocessing (e.g., along-track smoothing) and mapping process together with the choice of a mapping grid with finer scales than the mapped field can resolve ensures that there will be little variance of signal or noise at scales of a few grid points, so one cannot use the data-product grid in estimating the total number of spectral bands. (For example, we could interpolate the gridded data to an even finer grid, but this would not result in a meaningful change in the number of spectral bands or noise variance.) Given the record length in longitude and time and an effective longitude-time resolution of $2^{\circ}$ by 10 days, there are 15841 wavenumber-frequency bands. (This estimate includes only $8.75 \%$ of the bands that would be included if the total number of bands were naively estimated using the grid spacing of the mapped field.)

Given the number of spectral bands in the passband and the total number of spectral bands, the fraction of the total noise variance found within the passband should be, for white noise, $561 / 15841=3.54 \%$. If the noise in the gridded SSH product were white with a variance of $4 \mathrm{~cm}^{2}$, this would correspond to a root-mean-square noise amplitude of $3.76 \mathrm{~mm}$ within the passband. The white-noise

\footnotetext{
${ }^{6}$ There are subtleties in estimating the number of independent spectral bands contained in the passband because of the longitude zero padding north of $15^{\circ} \mathrm{N}$ and the tapering performed in the space-time and wavenumber-frequency domains. All of these will tend to reduce the number of independent spectral bands contained in the passband. All of the bands in the passband are treated as independent ones here, which is the conservative choice in the context of this discussion, because including more bands will lead to a higher noise estimate.
} 
variance would need to exceed $16 \mathrm{~cm}^{2}$, which seems unrealistically high, ${ }^{7}$ for the noise amplitude in the passband $(7.53 \mathrm{~mm})$ to begin to exceed the signal amplitude. The true noise spectrum is not known and is almost certainly not white, but it seems reasonable to conclude that the $O(1 \mathrm{~cm})$ signals seen in the filtered SSH field are not the result of bandpass filtering of random noise. This assertion is further supported by the apparent latitudinal coherence of the wavelike signal seen on $10^{\circ}-20^{\circ} \mathrm{N}$, the space-time localization of the signal, and the covariability of the signal with TIW activity near $5^{\circ} \mathrm{N}$, which would not be expected for random noise that was bandpass filtered in longitude and time.

\section{APPENDIX B}

\section{Discussion of Observed and Predicted Meridional Wavenumbers and Wave Crest Angles}

The difference between the correlation coefficients in the comparisons of observed and predicted meridional wavenumbers $(l$; Fig. 11) and wave crest angles $[\arctan (k / l)$; Fig. 12] requires some comment. Although both comparisons employ the value of the meridional wavenumber estimated from a least squares fit to the phase, the two comparisons are fundamentally different. The comparison of meridional wavenumbers tests the ability of the hypothesis to predict the meridional length scale, irrespective of the fact that the motions span a range of zonal wavelengths and periods $\left(9^{\circ}-23^{\circ}\right.$ of longitude and $26-38$ days), whereas the comparison of wave crest angles tests the ability of the hypothesis to predict the orientation of the wave crests (a quantity dependent on both zonal and meridional wavelengths).

Statistically, the difference in the correlation coefficients can be rationalized by noting that smaller meridional wavenumbers are loosely associated with larger zonal wavenumbers (e.g., by referring to the numbers relating the points in Fig. 11 to the points in Fig. 8), which makes the spread in values of crest angles more pronounced.

\footnotetext{
${ }^{7}$ The measurement error in the raw, $1-\mathrm{Hz}$ sea surface height measurements from the TOPEX/Poseidon and Jason-1 missions is thought to be about $17 \mathrm{~cm}^{2}$ (Chelton et al. 2001; Ménard et al. 2003). The errors in the European Remote Sensing Satellite-1 (ERS1), ERS-2, and Geosat Follow-On data are thought to be comparable after cross calibration against the Jason series altimeters (Le Traon et al. 1998, 2003). Additional errors are inevitably introduced in attempting to remove tidal and atmospheric pressure loading contributions (e.g., Ponte et al. 2007) and because of unresolved variability (e.g., eddies), but the total error should be substantially reduced by the averaging and gridding process used to make the AVISO gridded product.
}

Consider a case where only a single meridional wavenumber is excited over a range of zonal wavenumbers. If the meridional wavenumber were predicted perfectly but the estimated meridional wavenumber had a small amount of random noise, the correlation of observed and predicted meridional wavenumbers would be zero. In contrast, the predicted and observed crest angles would have a correlation near one. A fairly small range of meridional wavenumbers is present in this case, and the barotropic dispersion relation appears to do a reasonably good job of predicting the observed range.

Physically, the hypothesis suggests a reason why the observed range of meridional wavenumbers is small. The hypothesis involves the idea that the barotropic variability is coupled to the baroclinic variability (i.e., the TIWs) and that the frequency and zonal wavenumber of the barotropic variability and the baroclinic variability are the same. The TIW variability happens to be at frequencies and zonal wavenumbers near the dispersion curve of linear, first-baroclinic-mode, first-meridional-mode equatorial Rossby waves (Fig. 8; see also Lyman et al. 2005; Farrar 2008). The baroclinic Rossby wave dispersion curves shown in Fig. 8 are given approximately by (e.g., Gill 1982, p. 439)

$$
\omega=\frac{-\beta k}{k^{2}+\left(n+\frac{1}{2}\right) L_{D}^{-2}},
$$

where the equatorial deformation radius of the first baroclinic mode $L_{D}$ is $\sqrt{c_{1} / 2 \beta}$ and the first meridional mode corresponds to $n=1$. Comparison with Eq. (3) shows that, if the meridional wavenumber of the barotropic variability is equal to $\pm \sqrt{3 / 2} L_{D}^{-1}$, the corresponding barotropic dispersion curve will exactly coincide with the dispersion curve of first-baroclinic-mode, first-meridional-mode equatorial Rossby waves. For the value of the firstbaroclinic-mode gravity wave speed used to generate the curves in Fig. $8\left(c_{1}=2.7 \mathrm{~m} \mathrm{~s}^{-1}\right)$, this would correspond to a meridional wavenumber of $\pm 5.0 \times 10^{-6} \mathrm{~m}^{-1}$ (meridional wavelength of $11.2^{\circ}$ ). For zonal wavenumbers and frequencies lying above the first-baroclinic-mode, firstmeridional-mode equatorial Rossby wave dispersion curve, the meridional wavenumber of barotropic Rossby waves would be smaller. Because it is empirically true that the first-baroclinic-mode, first-meridional-mode equatorial Rossby wave dispersion curve passes through many of the zonal wavenumbers and frequencies where TIWs are excited, and this curve corresponds to a barotropic Rossby wave with a fixed value of the meridional wavenumber, the hypothesis thus explains the small range of meridional wavenumbers observed. 


\section{REFERENCES}

Bendat, J. S., and A. G. Piersol, 1986: Random Data: Analysis and Measurement Procedures. 2nd ed. Wiley-Interscience, $566 \mathrm{pp}$.

Bower, A. S., and N. G. Hogg, 1992: Evidence for barotropic wave radiation from the Gulf Stream. J. Phys. Oceanogr., 22, 42-61.

Brink, K. H., 1989: Evidence for wind-driven current fluctuations in the western North Atlantic. J. Geophys. Res., 94, 2029-2044.

Chave, A. D., D. S. Luther, and J. H. Filloux, 1992: The Barotropic Electromagnetic and Pressure Experiment 1. Barotropic response to atmospheric forcing. J. Geophys. Res., 97, 9565-9593.

Chelton, D. B., F. J. Wentz, C. L. Gentemann, R. A. de Szoeke, and M. G. Schlax, 2000: Satellite microwave SST observations of transequatorial tropical instability waves. Geophys. Res. Lett., 27, 1239-1242.

__ J. C. Ries, B. J. Haines, L.-L. Fu, and P. S. Callahan, 2001: Satellite altimetry. Satellite Altimetry and Earth Sciences, L.-L. Fu and A. Cazenave, Eds., Academic Press, 1-131.

—, M. G. Schlax, and R. M. Samelson, 2011: Global observations of nonlinear mesoscale eddies. Prog. Oceanogr., doi:10.1016/ j.pocean.2011.01.002, in press.

Cox, M. D., 1980: Generation and propagation of 30-day waves in a numerical model of the Pacific. J. Phys. Oceanogr., 10,11681186.

Ducet, N., P. Y. Le Traon, and G. Reverdin, 2000: Global highresolution mapping of ocean circulation from TOPEX/Poseidon and ERS-1 and -2. J. Geophys. Res., 105, 19 477-19 498.

Emery, W., and R. Thomson, 2001: Data Analysis Methods in Physical Oceanography. 2nd ed. Elsevier, 638 pp.

Farrar, J. T., 2008: Observations of the dispersion characteristics and meridional sea level structure of equatorial waves in the Pacific Ocean. J. Phys. Oceanogr., 38, 1669-1689.

— , and R. A. Weller, 2006: Intraseasonal variability near $10^{\circ} \mathrm{N}$ in the eastern tropical Pacific Ocean. J. Geophys. Res., 111, C05015, doi:10.1029/2005JC002989.

Foltz, G. R., J. A. Carton, and E. P. Chassignet, 2004: Tropical instability vortices in the Atlantic Ocean. J. Geophys. Res., 109, C03029, doi:10.1029/2003JC001942.

Fu, L.-L., and G. R. Flierl, 1980: Nonlinear energy and enstrophy transfers in a realistically stratified ocean. Dyn. Atmos. Oceans, 4, 219-246.

_ B. B. Cheng, and B. Qiu, 2001: 25-day period large-scale oscillations in the Argentine Basin revealed by the TOPEX/Poseidon altimeter. J. Phys. Oceanogr., 31, 506-517.

Gill, A. E., 1982: Atmosphere-Ocean Dynamics. Academic Press, 662 pp.

Halpern, D., R. A. Knox, and D. S. Luther, 1988: Observations of 20-day period meridional current oscillations in the upper ocean along the Pacific equator. J. Phys. Oceanogr., 18, 1514-1534.

Harrison, D. E., and A. R. Robinson, 1979: Boundary-forced planetary waves: A simple model mid-ocean response to strong current variability. J. Phys. Oceanogr., 9, 919-929.

Hristova, H. G., J. Pedlosky, and M. A. Spall, 2008: Radiating instability of a meridional boundary current. J. Phys. Oceanogr., 38, 2294-2307.

Kamenkovich, I. V., and J. Pedlosky, 1996: Radiating instability of nonzonal ocean currents. J. Phys. Oceanogr., 26, 622-643.

Kennan, S. C., and P. J. Flament, 2000: Observations of a tropical instability vortex. J. Phys. Oceanogr., 30, 2277-2301.

Killworth, P. D., and J. R. Blundell, 2004: The dispersion relation for planetary waves in the presence of mean flow and topography. Part I: Analytical theory and one-dimensional examples. J. Phys. Oceanogr., 34, 2692-2711.
LeBlond, P., and L. A. Mysak, 1978: Waves in the Ocean. Elsevier, $602 \mathrm{pp}$.

Le Traon, P. Y., F. Nadal, and N. Ducet, 1998: An improved mapping method of multisatellite altimeter data. J. Atmos. Oceanic Technol., 15, 522-534.

—, Y. Faugére, F. Hernandez, J. Dorandeu, F. Mertz, and M. Ablain, 2003: Can we merge GEOSAT Follow-On with TOPEX/Poseidon and ERS-2 for an improved description of the ocean circulation? J. Atmos. Oceanic Technol., 20, 889-895.

Luther, D. S., 1982: Evidence of a 4-6 day barotropic, planetary oscillation of the Pacific Ocean. J. Phys. Oceanogr., 12, 644-657.

—, A. D. Chave, J. H. Filloux, and P. F. Spain, 1990: Evidence for local and nonlocal barotropic responses to atmospheric forcing during BEMPEX. Geophys. Res. Lett., 17, 949-952.

Lyman, J. M., D. B. Chelton, R. A. deSzoeke, and R. M. Samelson, 2005: Tropical instability waves as a resonance between equatorial Rossby waves. J. Phys. Oceanogr., 35, 232-254

—, G. C. Johnson, and W. S. Kessler, 2007: Distinct 17- and 33-day tropical instability waves in subsurface observations. J. Phys. Oceanogr., 37, 855-872.

Malardé, J.-P., P. De Mey, C. Périgaud, and J.-F. Minster, 1987: Observation of long equatorial waves in the Pacific Ocean by Seasat altimetry. J. Phys. Oceanogr., 17, 2273-2279.

Malonette-Rizzoli, P., D. B. Haidvogel, and R. E. Young, 1987: Numerical simulation of transient boundary-forced radiation. Part I: The linear regime. J. Phys. Oceanogr., 17, 1439-1457.

Matsuno, T., 1966: Quasi-geostrophic motions in the equatorial area. J. Meteor. Soc. Japan, 44, 25-43.

McCreary, Z., and J. P. Yu, 1992: Equatorial dynamics in a 21/2layer model. Prog. Oceanogr., 29, 61-132.

McPhaden, M. J., 1996: Monthly period oscillations in the Pacific North Equatorial Countercurrent. J. Geophys. Res., 101, 63376359.

Ménard, Y., and Coauthors, 2003: The Jason-1 mission. Mar Geod., 26, 131-146.

Miller, A. J., and Coauthors, 2007: Barotropic rossby wave radiation from a model Gulf Stream. Geophys. Res. Lett., 34, L23613, doi:10.1029/2007GL031937.

Miller, L., D. R. Watts, and M. Wimbush, 1985: Oscillations of dynamic topography in the eastern equatorial Pacific. J. Phys. Oceanogr., 15, 1759-1770.

Musman, S., 1989: Sea height wave form in equatorial waves and its interpretation. J. Geophys. Res., 94, 3303-3309.

Niiler, P. P., J. Filloux, W. T. Liu, R. M. Samelson, J. D. Paduan, and C. A. Paulson, 1993: Wind-forced variability of the deep eastern North Pacific: Observations of seafloor pressure and abyssal currents. J. Geophys. Res., 98, 22 589-22 602.

Pascual, A., Y. Faugère, G. Larnicol, and P.-Y. Le Traon, 2006: Improved description of the ocean mesoscale variability by combining four satellite altimeters. Geophys. Res. Lett., 33, L02611, doi:10.1029/2005GL024633.

Pedlosky, J., 1977: On the radiation of meso-scale energy in the mid-ocean. Deep-Sea Res., 24, 591-600.

_ 1987: Geophysical Fluid Dynamics. 2nd ed. Springer-Verlag, $710 \mathrm{pp}$.

Périgaud, C., 1990: Sea level oscillations observed with Geosat along the two shear fronts of the Pacific North Equatorial Countercurrent. J. Geophys. Res., 95, 7239-7248.

Philander, S. G. H., 1978: Instabilities of zonal equatorial currents, 2. J. Geophys. Res., 83, 3679-3682.

Ponte, R. M., C. Wunsch, and D. Stammer, 2007: Spatial mapping of time-variable errors in Jason-1 and TOPEX/Poseidon sea 
surface height measurements. J. Atmos. Oceanic Technol., 24, 1078-1085.

Price, J. F., and H. T. Rossby, 1982: Observations of a barotropic planetary wave in the western North Atlantic. J. Mar. Res., 40 (Suppl.), 543-558.

Proehl, J. A., 1996: Linear stability of equatorial zonal flows. J. Phys. Oceanogr., 26, 601-621.

Qiao, L., and R. H. Weisberg, 1995: Tropical instability wave kinematics: Observations from the Tropical Instability Wave Experiment. J. Geophys. Res., 100 (C5), 8677-8693.

Samelson, R. M., 1990: Evidence for wind-driven current fluctuations in the eastern North Atlantic. J. Geophys. Res., 95, 11 359-11 368.

Shinoda, T., G. N. Kiladis, and P. E. Roundy, 2009: Statistical representation of equatorial waves and tropical instability waves in the Pacific Ocean. Atmos. Res., 94, 37-44.

Smith, K. S., and G. K. Vallis, 2001: The scales and equilibration of midocean eddies: Freely evolving flow. J. Phys. Oceanogr., 31, 554-571.

Song, Y. T., and V. Zlotnicki, 2004: Ocean bottom pressure waves predicted in the tropical Pacific. Geophys. Res. Lett., 31, L05306, doi:10.1029/2003GL018980.

Spall, M. A., 1992: Rossby wave radiation in the Cape Verde frontal zone. J. Phys. Oceanogr., 22, 796-807.

Sun, C., W. D. Smyth, and J. N. Moum, 1998: Dynamic instability of stratified shear flow in the upper equatorial Pacific. J. Geophys. Res., 103, 10 323-10 337.
Sutherland, B. R., C. P. Caulfield, and W. R. Peltier, 1994: Internal gravity wave generation and hydrodynamic instability. J. Atmos. Sci., 51, 3261-3280.

Tai, C.-K., and W. B. White, 1990: Eddy variability in the Kuroshio Extension as revealed by Geosat altimetry: Energy propagation away from the jet, Reynolds stress, and seasonal cycle. J. Phys. Oceanogr., 20, 1761-1777.

Talley, L. D., 1983a: Radiating barotropic instability. J. Phys. Oceanogr., 13, 972-987.

- 1983b: Radiating instabilities of thin baroclinic jets. J. Phys. Oceanogr., 13, 2161-2181.

Warren, B. A., T. Whitworth III, and J. H. LaCasce, 2002: Forced resonant undulation in the deep Mascarene Basin. Deep-Sea Res. II, 49, 1513-1526.

Weijer, W., 2008: Normal modes of the Mascarene Basin. Deep-Sea Res. I, 55, 128-136.

—, F. Vivier, S. T. Gille, and H. A. Dijkstra, 2007: Multiple oscillatory modes of the Argentine Basin. Part I: Statistical analysis. J. Phys. Oceanogr., 37, 2855-2868.

_ S. T. Gille, and F. Vivier, 2009: Modal decay in the AustraliaAntarctic Basin. J. Phys. Oceanogr., 39, 2893-2909.

Wunsch, C., 1997: The vertical partition of horizontal kinetic energy. J. Phys. Oceanogr., 27, 1770-1794.

Yu, Z., J. P. McCreary, and J. A. Proehl, 1995: Meridional asymmetry and energetics of tropical instability waves. J. Phys. Oceanogr., 25, 2997-3007. 